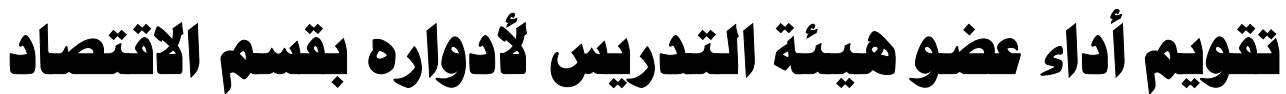

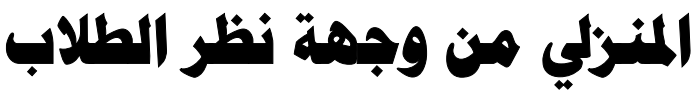 \\ أ.د/الحنال مسني يشار

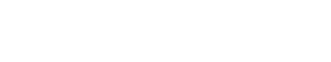 \\ ووكلى كلية النربية النوعية - \\ الشئهن النمليم ولاللاب -جالمعة المنوفية
}

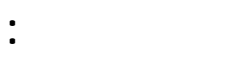

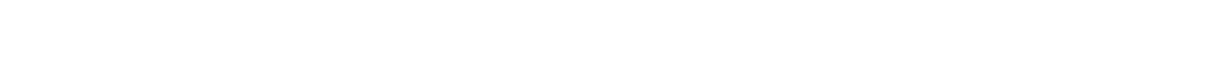

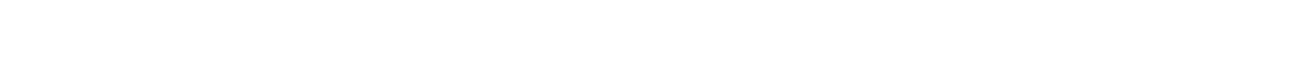

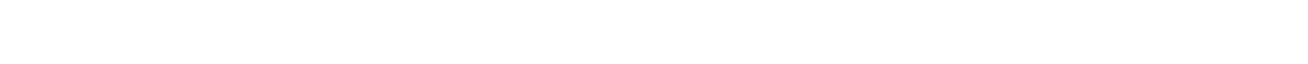

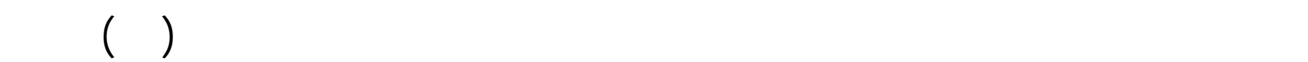

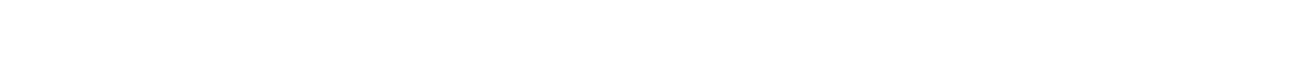

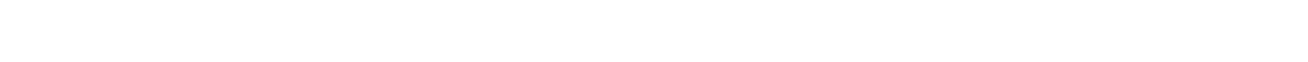

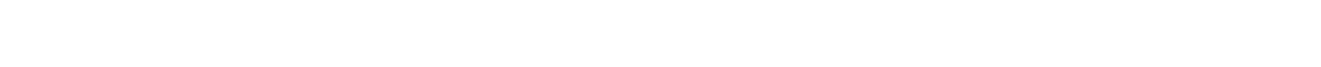

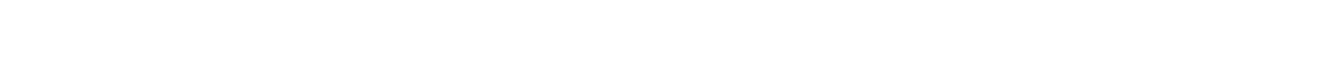

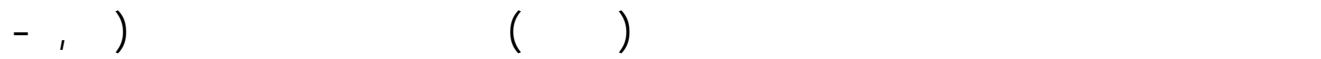

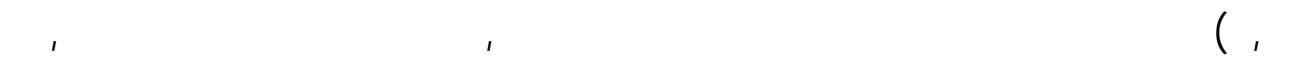

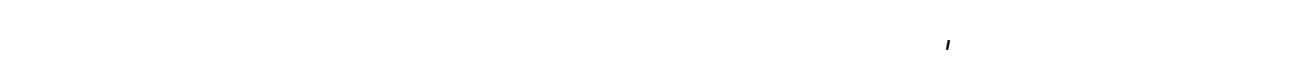

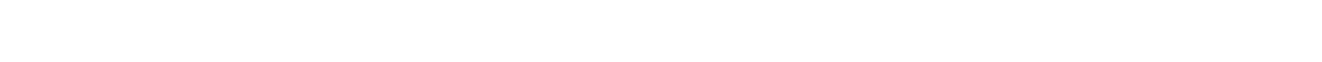

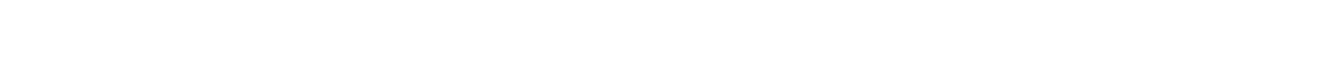

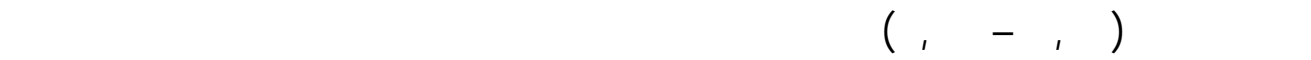

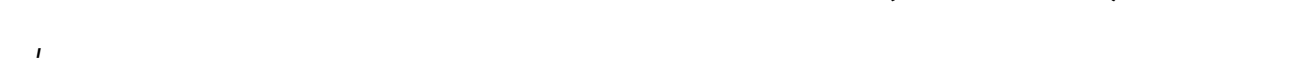

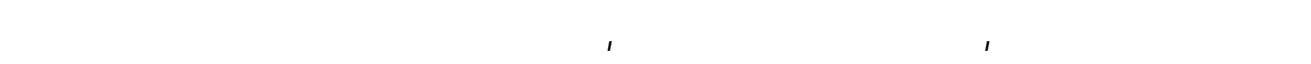

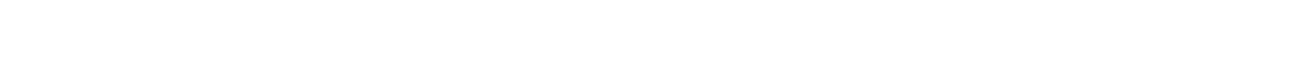

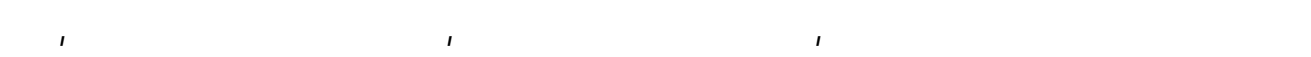

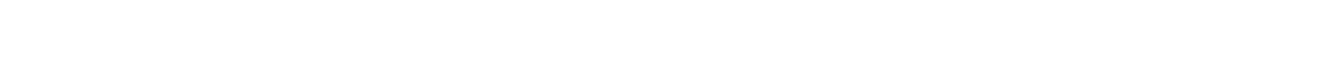

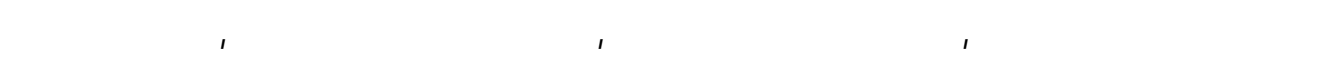

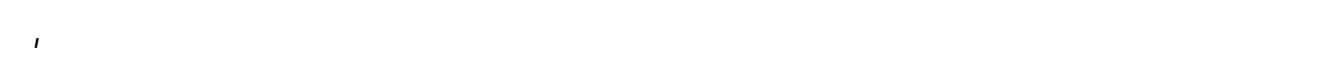

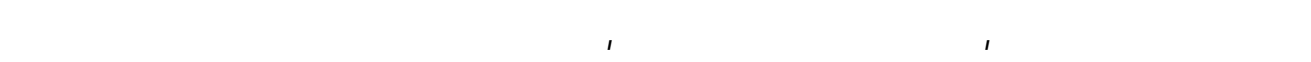

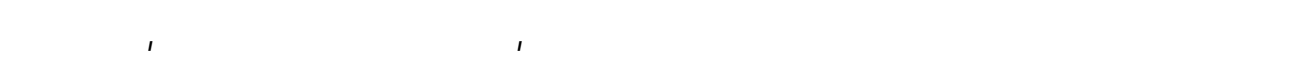

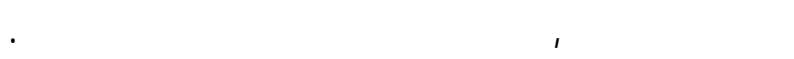




\section{Research Summary :}

The research aims to identify the performance of the faculty level by using the tool to evaluate the performance of the faculty members of the Home Economics Department Faculty of Specific Education, Menoufia University, from the standpoint of undergraduate and graduate students, where the researcher prepared after reviewing previous studies in this area and formed the tool of the five areas of (0.) paragraph, has the researcher to apply the tool on the research sample, which consisted of undergraduate and graduate students in the Department of Home Economics and the total sample $V \vee$ students have used the researcher the necessary statistical methods and reached a set of results from the most important performance came faculty level evaluation Department of Home Economics, Faculty of Specific Education Menoufia University of perspective of students degree (high) and confined between appreciation class $\left(\Gamma, T V_{-} 0, \cdots\right)$, reaching the arithmetic average of the areas of the Faculty of $r, v \leqslant$ and a standard deviation of 1,11 , and the weight percentage of $\$ \vee \varepsilon, \wedge \varepsilon$, and ranged from the arithmetic mean of the responses of the respondents from the students section home Economics Faculty of Specific Education Menoufia University on areas that represent evaluating the performance of faculty members at the Department of home Economics, Faculty of Specific Education, University of Menoufia between $(r, \leqslant q-r, \wedge \wedge)$, where the field way feed scientific material came in first place for the areas of evaluating the performance of faculty level a mean was $r, \wedge \wedge$ and standard deviation 1,11 weight relative value of $\vee v, 0 r$, where the score is high, and followed in the order in the field of recipes faculty member in the second arrangement for those areas with a mean was $r, \wedge \leqslant$ and standard deviation $1, \cdot \wedge$ and weigh the relative value of $\checkmark \neg, 9 r$, where the score is high, followed by the field teaching methods used in third place with a mean reached $r, \vee q$ and standard deviation $1, \wedge \wedge$ and weight relative worth $\vee 0, \wedge 1$ where the score is high, then the area of the calendar in the fourth position with a mean reached $r, v$ and standard deviation $1, \times \wedge$ and weight relative worth $\vee \leqslant, 19$ where the score is high, and finally the field of university book My average was $r, \Sigma 9$ and $1,1 \wedge$ standard deviation and relative weight value of $\neg 9, \vee \leqslant$, where the degree of medium-evaluation . 
إن جودة مخرجلت التعليم تمل المطك الذي يحكم به على جوة أداء التعليم الذي

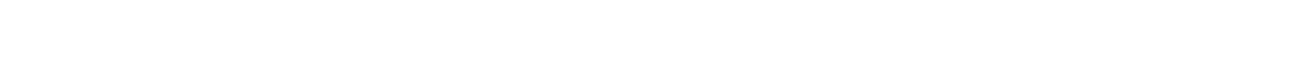
التخاذ القرارات، ومساعة الطلاب في لختيار الأفضل للمقررات الدرلسية، ومساعة ولفية أعضاء هيئة التدريس في ظوير كفايلتهم التدريسيه.

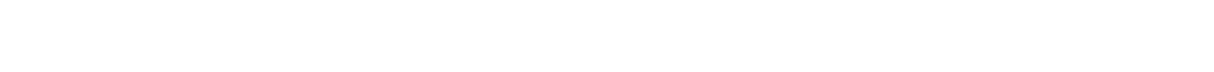

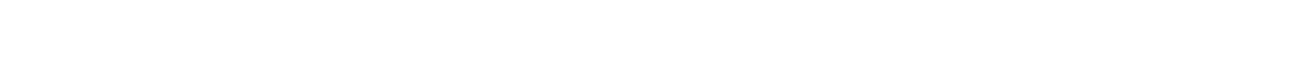
هيئة التدربيس في المجالين البحثي وخلمة المجتمع من جهة لخرى .وتتعددط الخرق ووسائ.

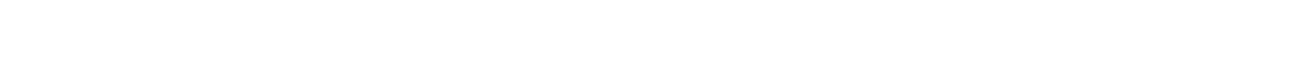

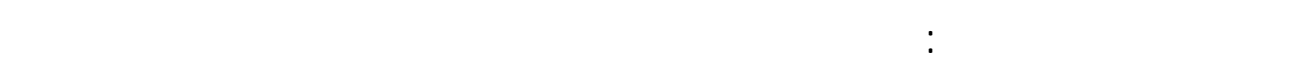

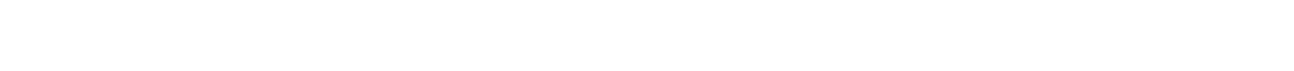

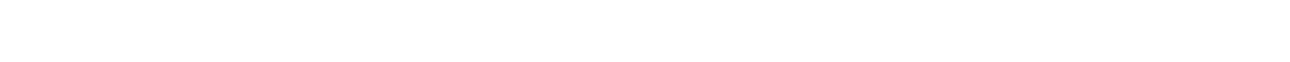

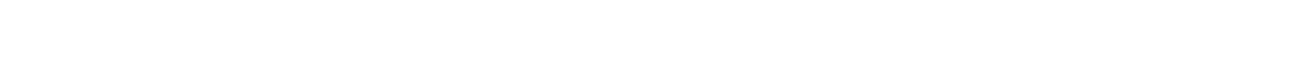

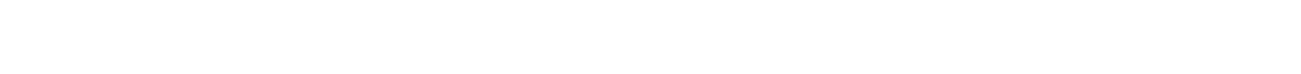

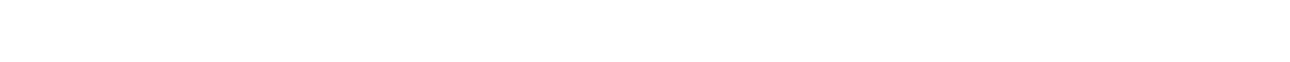
والإنترنت لزيادة فاعلية تدريسه وبحثه، ومدى حرصه على قطوير لختباراتهسواء لكان

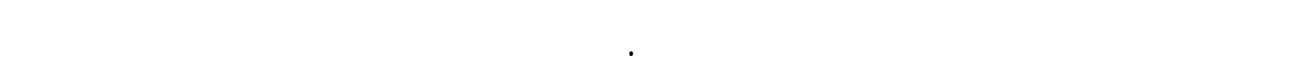

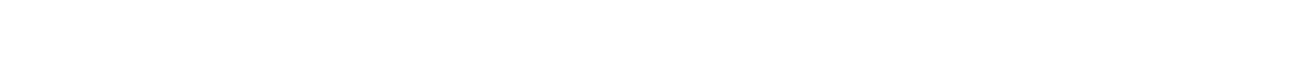
متاح، لم بتمكين الطالاب من الإسفاة من خبراته وتحفيزهم على الإبداع وتحسين قدراتهر

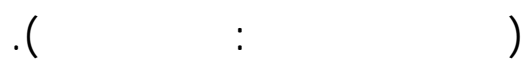
إن الإطار المقترح يلخذ بالهسبان الوصف الوظيفي لعضو هيئة التدربيس وولجباته الأكاديمية والإدارية، فيقوم كل المهلم والولجبات والمسؤوليت التي يضلع بها عضو هيئة

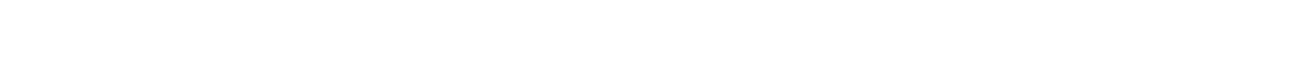
ومشاركته في تضطيط عملية ققويم عضو هيئة التدربيس وتظيمها وتوجيهها إلى رقابتها. وكذلك يأخذ بالحسبلن التصنف الوظيفي حتى يضيف عضو هيئة التدربس إضلفة نوعية للعملية التدريسية والبحثية وخلمة المجتمع، مما يسهر في ظوير الجلمعة التي ينتمي إليها. 
إن عملية القويم توفر تغنية رلجعة للك من عضو هيئة التدربيس والجلمعة عن الأداء

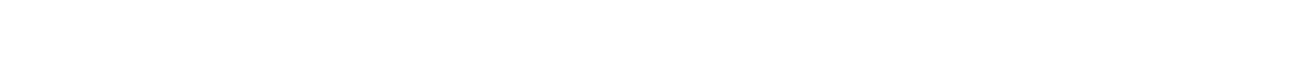

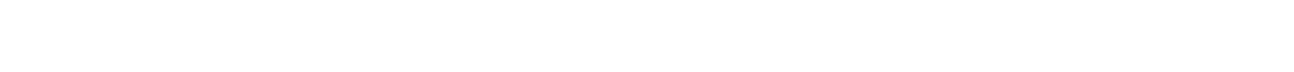

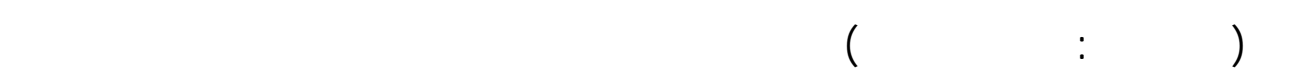
وتكتثف الجلمعة معه الأعضاء الذنن يتمتعون بصفلت قيادية أو إستثنائية يمكن الإستفادة

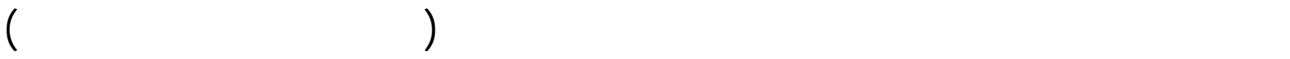

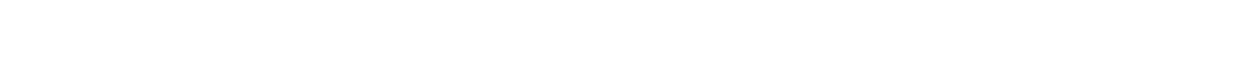

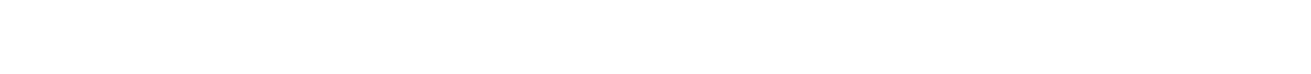
الرئيسي في إحداث تغيرات تربوية لدى طلاب وطالبلت قم الاقتصاد المذزلي. ولأهمية الدور الذي يقوم به عضو هيئة التدربيس في الجلمعلت كلن لابد من لستخده المصادر

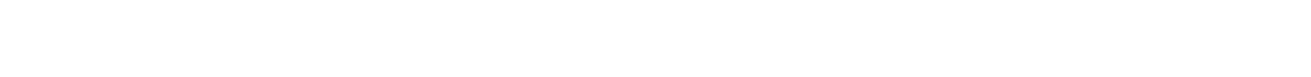
الأداء التدريسي لعضو هيئة التدريب الجلمعي دلخل القاعلت. إن من أقوى المصادر في قويم الأداء التدريسي لعضو هيئة التدربيس هي: رؤساء

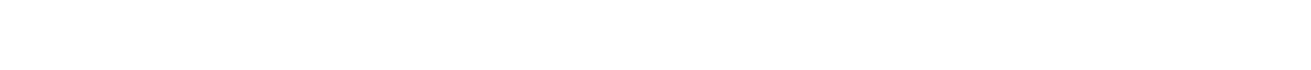

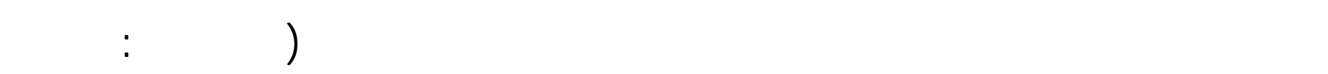

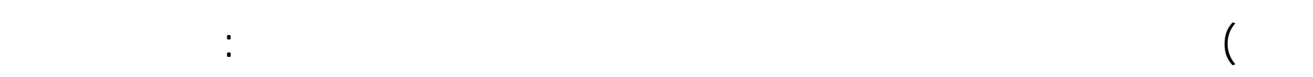
تقيم الطلاب المصدر الأسلسي للمعلوملت لأنه المتلفي المبلثر لمحاثة عضو هيئة

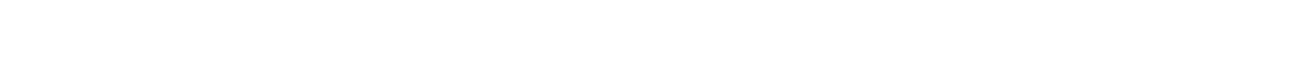

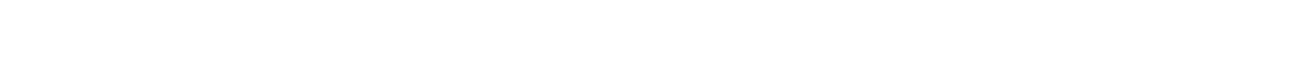

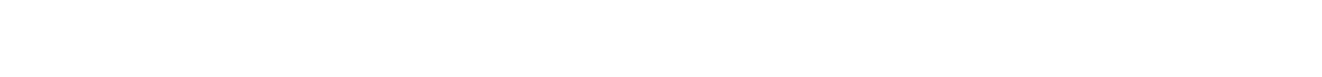

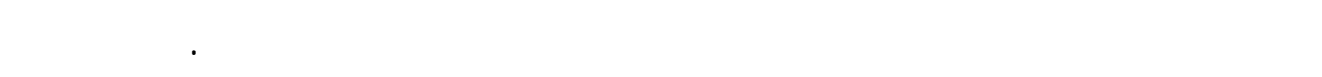

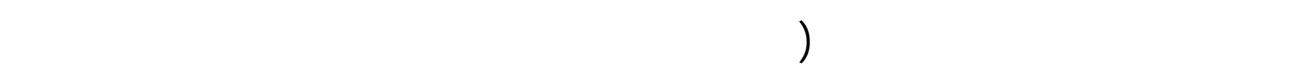
الصفلت للثخصية،طرق ولنساليب التدريب، الفاعل مع الطالب، العلاقلت الإنسانية).

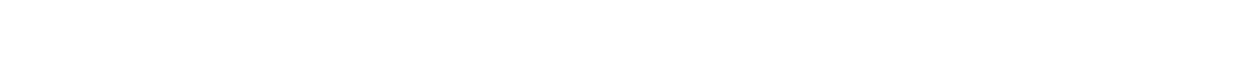

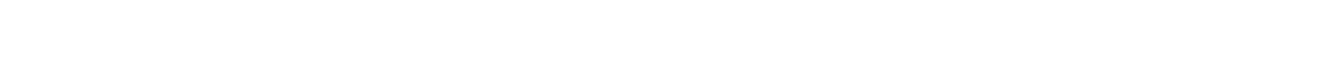

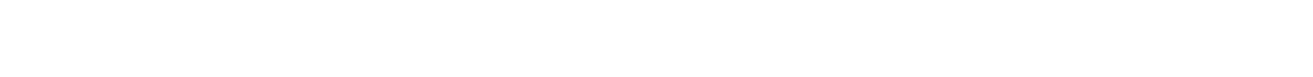

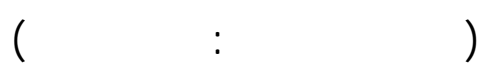


إن المتوارث من أن قييم أداء أعضاء هيئة التدربيس مرّه إلى الإيملن بئن عضو ألهو هيئة التدربيس ينبغي ألا يتعرض أو يخضع للقييم، حيث أن له الحرية بأن يقوه بأداء ولجباته بالطريقة والكيفية التي تنلسبه في اعنقاه، وما زالت الجلمعلت تستخدم الطريقة الثقليية في ققويم أداء عضو هيئة التدريب، وعليه جاء هذا البهث لإثراك المحور المهز في قويم عضو هيئة التدريب وهم الطلاب. وققيم الطلاب له مساهمة إيجابية في طظوير أداء عضو هيئة التدريس، لذاك كلن لابد من فقيم أداء عضو هيئة التدربيس من وجهة ظقر

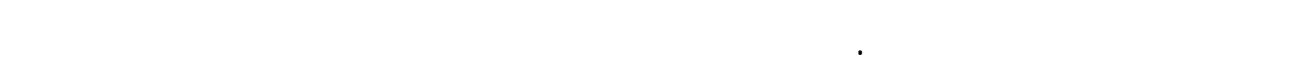

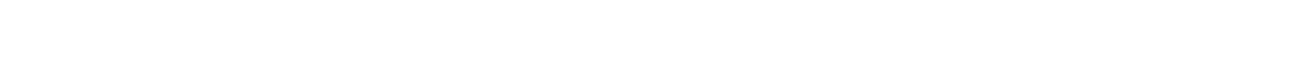

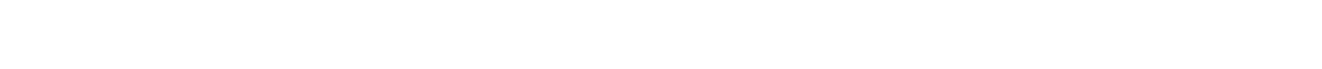
التدربي في تحقيق أهدف الجلمعة وخاصة في إعداد وبناء مخرجلت تلبي لحتيلجلت المجتمع ومظلباته المختلفة من هنا أدركت البلحثة مشكلة فقويم الأداء لعضو هيئة التدربيس ولجراءات تمسينه وما يدقهه من انعكلسات على جودة التعليم فإن مشكلة البحث تتبلور في التساؤل الرئيسي الآتي: ما مستوى أداء عضو هيئة التدريب لأدوارو بقم الاقتصاد المذزلي بكلية التربية

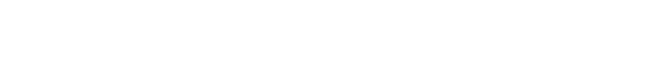
ويقرع من هذا للسؤل التساؤلات الفرعية التالية: 1 - ما مدى قيلم عضو هيئة التدريب بدوره بقم الاقتصاد المنزلي بكلية التربية الذوعية جلمعة المذوفية من وجهة ظرطلابه من حيثطرق التدربيس المستخلمة؟. r - ما مدى قيل عضو هيئة التدربيس بدوره بقم الاقتصاد المذزلي بكلية التربية الذوعية جلمعة المذوفية من وجهة ظطرط لمالبه من حيث المادة العلمية؟ ب - ما مدى قيل عضو هيئة التدربيس بدوره بقم الاقتصاد المذزلي بكلية التربية الذوعية

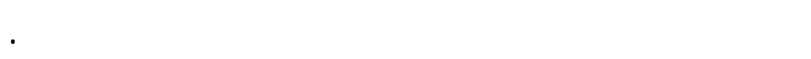
ع - ما مدى قيلم عضو هيئة التدريس بدوره بقم الاقتصاد المذزلي بكلية التربية النوعية جلمعة المذوفية من وجهة ظطرطلابه من نلحية الكتلب الجلمعي؟. 0 - هل توجد فروق فرية في لستجابة أفراد العينة تبعاً للمرحلة(البكالوريوس/الدربلست العابه العليا)؟. 
تقويم أداء أعضاء الهيئة التدريسية لأدواره في قصم الاقتصاد المذزلي بكلية التربية

النوعية جلمعة المذوفية من وجهة ظظرطلبة البكالوريوس والدرلست العليا .

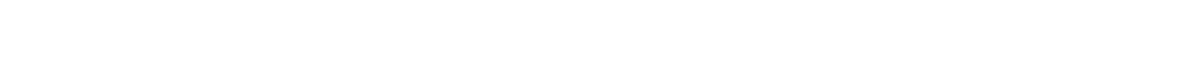
ققط القوة.

\section{لهمية البحث:}

\section{ترجع أنهية هذا البهث إلى:}

- إبراز أهمية القويم لأداء عضو هيئة التدربيس كونه مقدمة ضرورية، بل ولسلسية لأي عملية ظويرية في التعليم الجلمعي. - عملية ققويم أداء أعضاء هيئة التدربيس عملية مفيدة لأعضاء هذه الهيئة أفنهم فضلاً عن ظطوير وتمسين الطرق والمبادئ التربوية التي يستخلمونها، وذك من خلل التعرف هينة

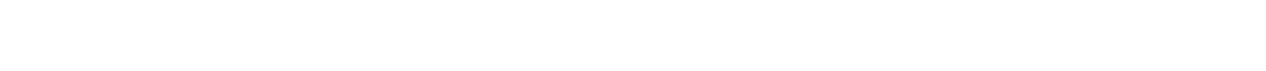
غاياتها العليا. - تلبية حلجة قنم الاقتصاد المذزلي إلى إجراء درلسة علمية تكثف عن أداء أعضاء هيئة التدربس بالقنم خاصة حيث أن الكلية تسعى جاهلة إلى تجويد مخرجاتها التعليمية مما يظلب الوقوف على المعوقت والإمكانيت المتلحة لها من الكفاءات. - الإثارة إلى مشكلات جديرة بالبهث والقصي والتي قد قطهر من خلال إجراء هذه الدرلسة مما يؤدي إلى تتايع وتكلمل المعرفة في هذا المجل.

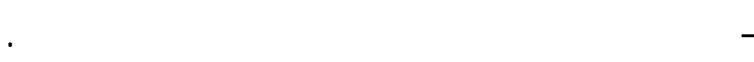
- تحفيز عضو هيئة التدربس على الأداء المتميز لمعرفته لجوانب القوة والضعف في الذبه أدائه لأدوارهمن مظور الطلاب.

\section{منهج البهث:}

اعتمدت البلحثة على المنهج الوصفي كونه يعد من أفضل المناهج التي تحقق النتائج الملوبة في مل هذه الأبحك والدرلست. 


\section{حدود الررلسة:}

- اقتصرت هذه الدرلسة علىطلبة البكالوريوس الفرق الأريع والدرلسلت العليا(الدبلوم

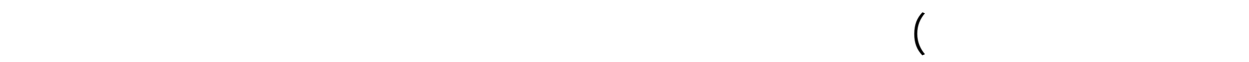

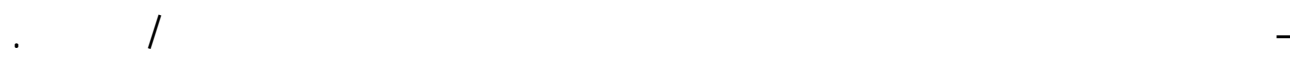
- القتصر القويم علمستة مجالات هي (طررق التدريس المستخمة، صفات عضو هيئة التدربس،طريقة تخنية المادة العلمية، القويم، الكتاب الجلمعي). مصطلحلت البهث: القوم: في اللغة :القويم من أصل قوّم، بمعف قدر قيمته، وقوّم اللثيء وزنه (البن

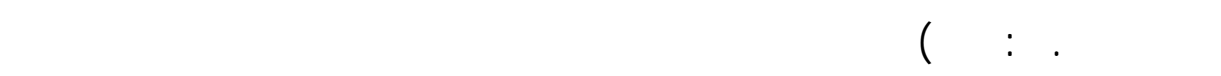
والقصد من ذلك معرفة إلى أي مدى لسفاد الطلبة من العملية التعليمية وما مدى

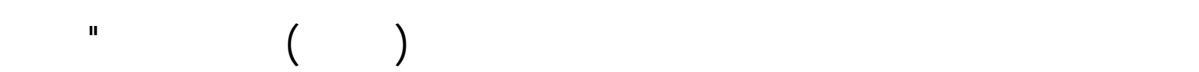

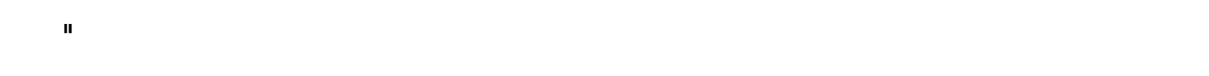

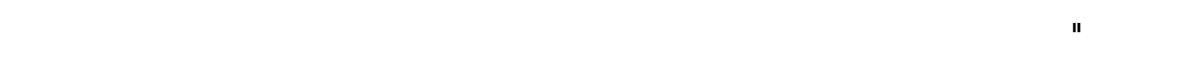

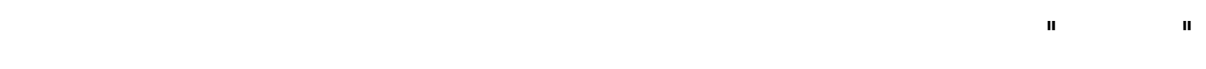

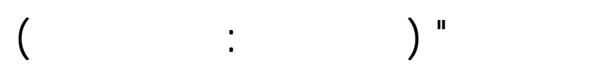
الأداء: تعني كلمة" أداء "في قلموس المنجد، إيصل اللثيء إلى الم المبسل إليه، وتربوياً تعني

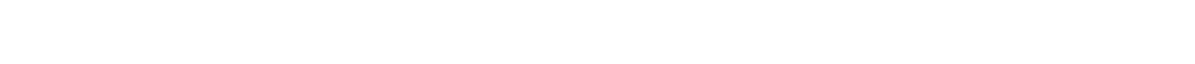

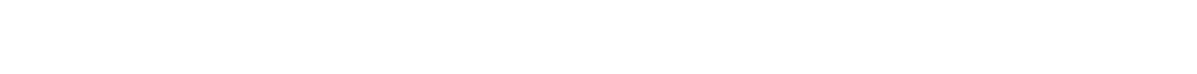

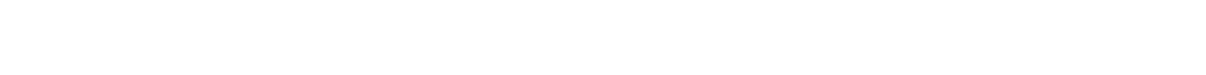

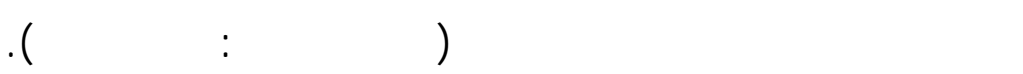

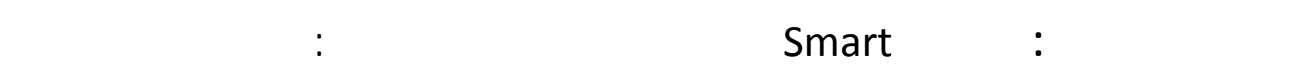
التعليمية التي يقوم بها الأساتنة الجلمعيون(العمليت التدريسية) والتغيير التعليمي Smart: ) الحاطل والذي يظهر على سلوك الطلبة كظظر لنتائج التدربيس 
كما عرفته (الجفري) بأنه كل ما يقوم به عضو هيئة التدربيس من لنثطة، وعمليت، وإجراءات، وسلوكيت تعليمية تتعلق بعملية التدريب دلخل الصف الدرلسي وخارجه

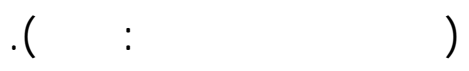

كما عرفه (للسيد علي) بأنه الطريقة التي يتحدد من خلالها كيفية تحقيق نشطل من قل

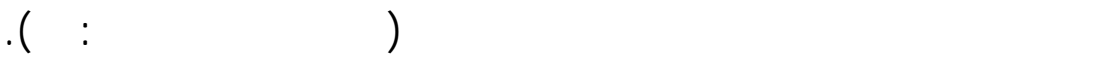
هوم الأداء: إن عملية القويم ضرورية ومهمة بوصفها جزءَ لا يتجزأ من عملية ظطوير العملية التعليمية بالجلمعلت، وبدونها لا يمكن التعرف على مدى تهقيق أهداف تالك الجلمعلت في رفع المستوى التعليمي. ولهذا فإن نقويم التعليم في الجلمعلت أصسح ضرورة حتمية اليوم والذي بدوره يعتمد على تقويم أداء عضو هيئة التدربيس

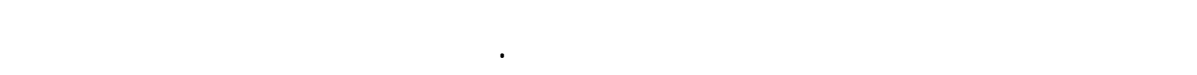

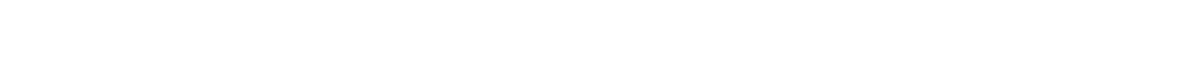
لأنهم الأكثر تعرضاً لأدائه وهم المسقفيدون بالدرجة الأوله من ذالك الأداء، كما أنهم ألماء

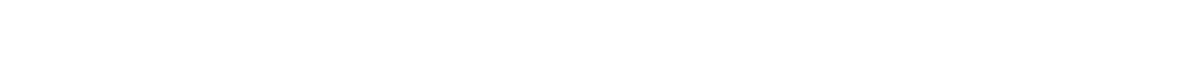

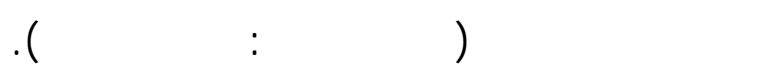

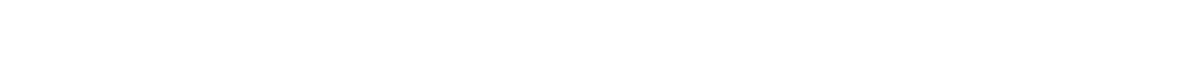
عضو هيئة التدريس يؤدى عمله عند مستوى لا يقل عما تحدده المعايير التربوية

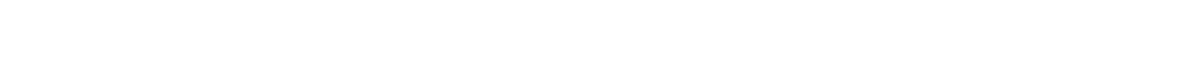

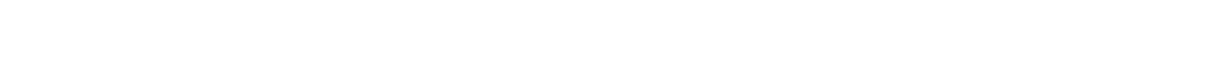
حيث يقم تقويم عضو هيئة التدربيس حول نشلطه التدريسي، وأعماله البحثية،

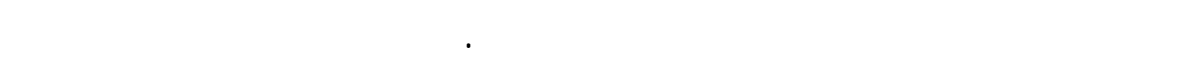

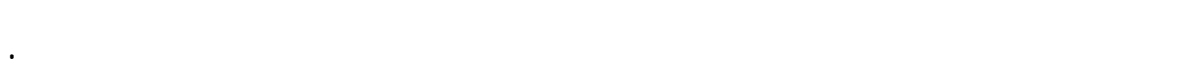

\section{رلرالتسساقةة:}

لجريت العديد من الدرلسلت حول نقويم الأداء التدريسي في مرلل التعليم كلفة من

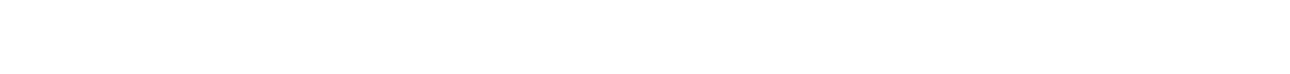
العلاقة بموضوع بحثه. 


\section{I - درلسة خالد الصرليرة I 1 -r: الأداء الظليف لهى أعضاء الهيئلت التربسية في}

\section{الجامعلت الأرنية الرسميةمن وجهة ظالر رؤساء الأفسله فبها .}

هدفت الدرلسة إلى التعرف على مستوى الأداء الوظيفي لأعضاء الهيئة التدريسية في

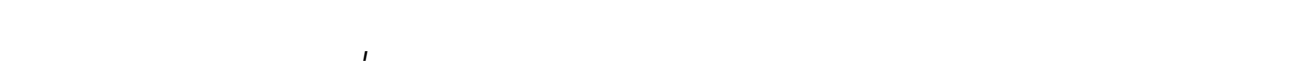
لجمع لمعلوملت.طقت على عينة مكونة من (VV) رئيس قم ألخاديمي قم لختيارهم بالطريقة العشوائية البسية، ولستخهم المنهج الوصفي التحليلي ,وكانت أبرز نتائج الدرلسة ما بلي: أن مستوى الأداء الوظيفي لدى أعضاء هيئت التدريس من وجهة ظرر رؤساء أقسلمهز بشكل علم كان مرتقعاً, وهومؤشر جيد على توفر المناخ التظيمي الجلمعي للسليم لأعضاء هيئة التدربيس.

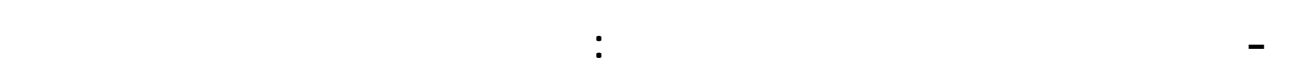
التربس في أفسل كلية التربية بجامعة لٔ الفرى من وجهة ظلرطلاب ولالبلت

\section{مرحلة المكتورd.}

هدفت الدرلسة إلى ققيم أداء أعضاء هيئة التدريس من وجهة ظرطلاب الكتوره

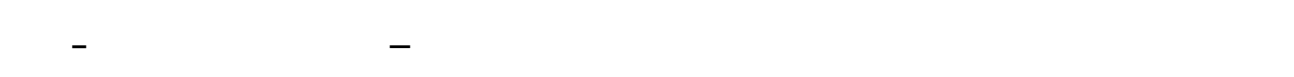

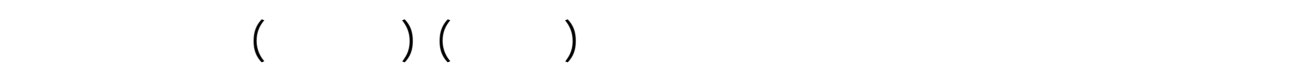
التي توصل إليها البلحث في الدرلسة أن لأسلوب التعلطل مع الطلاب والطالبت لحنل المرتبة الأوله. م - درلسة دالود عبد المك الحدابي، خالد عمرخلن A - . r: قوم الاللب لأداء أعضاء هيئة الثربس بجامعة العلوم والتكنولوجيا اليمنية في ضوء بهون بهن الهمليلت التربسية هذفت إلى التعرف على مستوى أداء أعضاء هيئة التدريس بجلمعة العلوم والتكنولوجيا اليمنية من خلال رأي الطلاب في ضوء بعضن الفوض الكفايت التدريسية ,وقد لستخدت لهذا الهذف لستبانه مكونة من r ب فقرة مقسمة إلىستة كمايلت تدريسية(التعليم، التغنية الرلجعة، الدعم الأكايمي، إدارة المحاضرة، مصادر التعله، التنمية للشخصية)

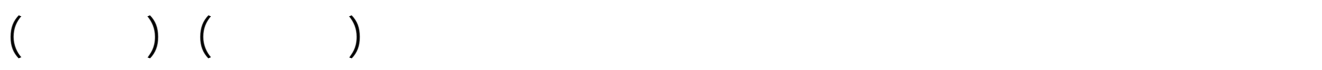


قم لختيارهم طبريقة العينة العثوائية الطقية، وقد لظهرت نتائج الدرلسة عدم وجود فروق ذات دلالة إحصائية بين متوسطات درجلت أعضاء هيئة التدربيس تتعزى إلى متغير المؤهل

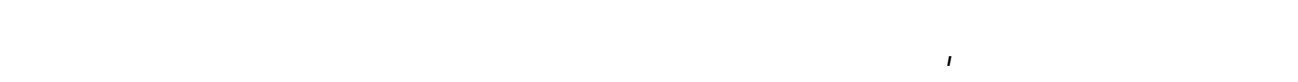
متوسطلت درجلت أعضاء هيئة التدريب تعزى إله متغير النوع عند مستوى الدلالة 0 . ,

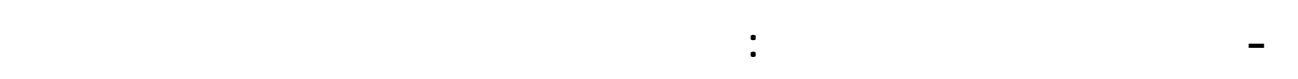
وجامعة ولاية فلوربدا الأمربكية"

هدفت الدرلسة إلى التعرف على معايير نقويم عضو هيئة التدربس في جلمعة لم القرى وجلمعة فلوريدا والتعرف على أوجه الاتفلق والاختلاف بين المعايير وتوضبح الايجابيت وللسلبيت في أظمة القويم في الجلمعتين.

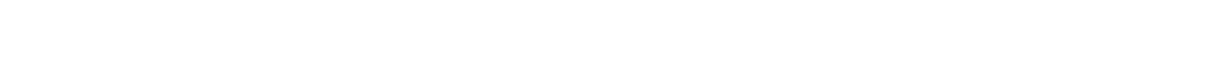

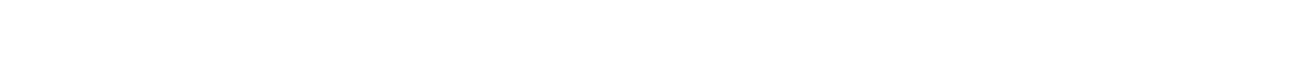

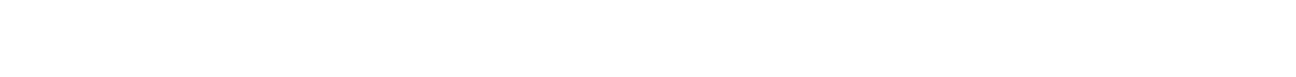
ولستكشف الأخطاء. 0 - درلسة محمد الهمليرة ب . . م : بعنولن" التجاهلت أعضاء هيئة التدربس في جاهمة

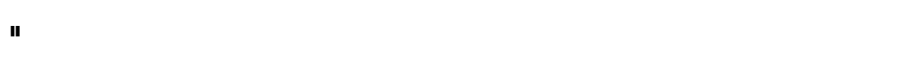

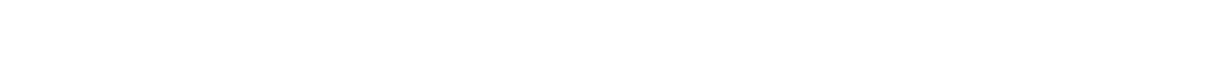
الأردن نحو تقيم الطلبة لأدائهم التدريسي، والعولمل المؤثرة في عملية القيم، وبلغ حهم فئه العينة VOعضو هيئة تدربيس وشكلت 9,ع \% \% من حجه مجتمع الدرلسة الأصلي، وكانت أهم النتائج:

إن التجاهلت أعضاء هيئة التدريب نحو فقيم الطلبة لأدائهر بشكل علم جاءت محاية , كما جاءت اتجاهاتهم في بعض الفقرات إيجابية في الجوانب التالية( نقيم الطلبة لأداء

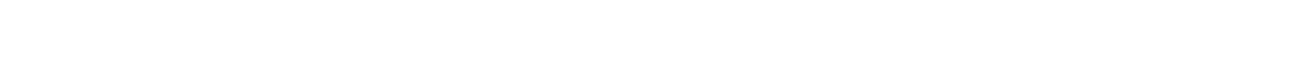
الطلبة لأداء عضو هيئة التدربيس، وان تستمر إدارة الجلمعة في ظبيق لأسلوب تقييم الطلبة

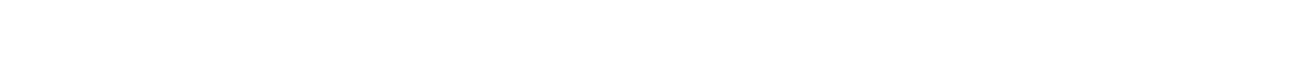
الطالب. وجاءت اتجاهاتهمسلبية في جولنب لخرى وهي عدم تأثير اتجاهات أعضاء هيئة التدربيس نحو ققيم الطلبة لأدائهر تبعاً للمتغيرات: الكلية التي يدوس فيها عضون وهي هيئة 
التدريب، الجنس، الخبرة في التدربي، الجلمعة التي تخرج منها عضو هيئة التدريب، المؤهل العلمي لعضو هيئة التدربيس.

\section{نيتائج الدرلسة وفسيرها}

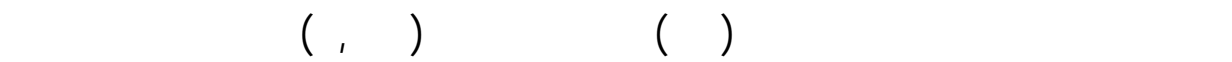
التي مَ نكرهاسابقاً، وبالتالي إذا كافت درجة المتوطط الهسابي والوزن المئوي للمجل ككل ألقل من المتوسط الفرضي ووزنه المئوي فيكون المجل في حلجة إله تعديل.

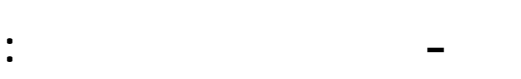

(1) جل

يوضنحقيمة المتوط المسلب ولانحره المعياري والون المئوي والترتيب ودرجة قيم المبحوثن لهستوى

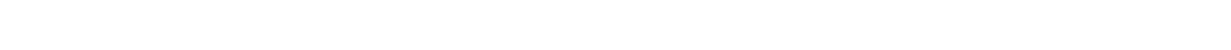

\begin{tabular}{|c|c|c|c|c|c|}
\hline لرجة & الترتيب & الونن & لالنحرف & المتوطحا & محاور القيلس \\
\hline مرتقعة & $\mu$ & $\mathrm{VO}, \Lambda \mathrm{I}$ & 1,1 & ए,Vq & مجلطرق التربس المستخلمة \\
\hline مرتقعة & $r$ & vา,9 & $1, \cdot 1$ & $\Psi, \wedge \varepsilon$ & مجل صفلت عضو هيئة التدربس \\
\hline مرتقعة & 1 & $\mathrm{VV}, \mathrm{OH}$ & 1,11 & ${ }^{\mu}, \Lambda \Lambda$ & مجلطرقة تغنية المالة العامية \\
\hline مرتقعة & $\varepsilon$ & $V \varepsilon, I V$ & $1, \cdot 1$ & I,VI & مجل القوم \\
\hline متوسطة & 0 & $79, V \varepsilon$ & 1,11 & ऍ,દ૧ & مجل الكتلب الجاهمي \\
\hline مرتقعة & --- & $V \varepsilon, \wedge \varepsilon$ & 1,11 & $\mu, \mathrm{r} \varepsilon$ & وع الهل \\
\hline
\end{tabular}

يتضح من الجدول السابق أن ققيم طستوى أداء أعضاء هيئة التدربيس بقم الاقتصاد المنزلي بكلية التربية النوعية جلمعة المنوفية من وجهة ظار الطلاب كانت بدرجة (مرنفعة) وتنحصر بين فئة القدير (

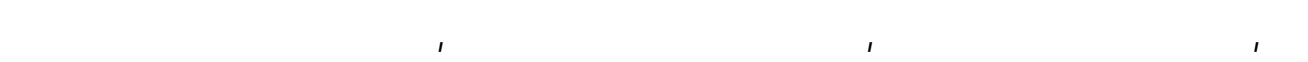

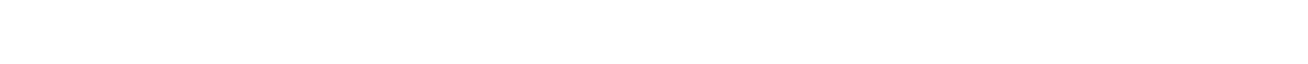

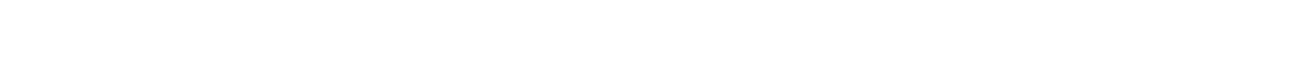

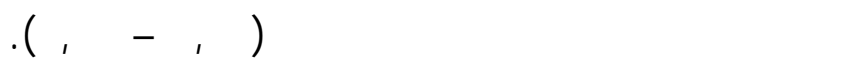
وكلن مجل طريقة تقديم المادة العلمية في الترتيب الأول بالنسبة لمجالات تقيم مستوى أداء أعضاء هيئة التدربيس بقم الاقتصاد المززلي بكلية التربية النوعية جلمعة

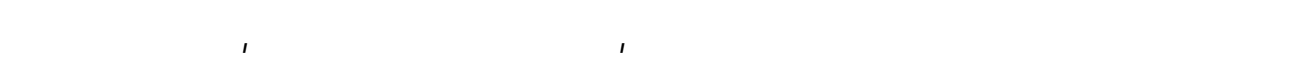
قيمته WV,OH حيث كلت درجة القيم مرتفعة، وجاء مجل صفلت عضو هيئة التدربيس 
في الترتيب الثاني بالنبة لمجالات ققيم مستوى أداء أعضاء هيئة التدربيس بقم الاقتصاد

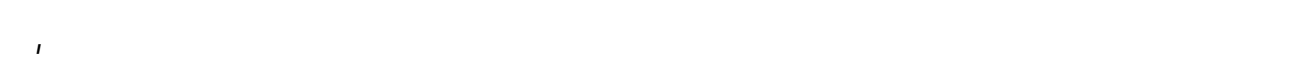

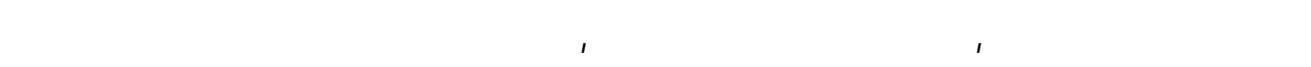
وجاء مجل طررق التدريب المستخلمة في الترتيب الثالث بالنسبة لمجالات فقيم مستوى أداء أعضاء هيئة التدربيس بقمم الاقتصاد المذزلي بكلية التربية النوعية جلمعة المنوفية،

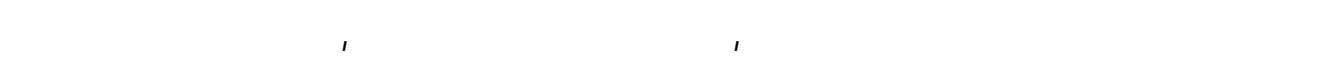
V0,1 لمجالات تقيم مستوى أداء أعضاء هيئة التدربيس بقم الاقتصاد المذزلي بكلية التربية

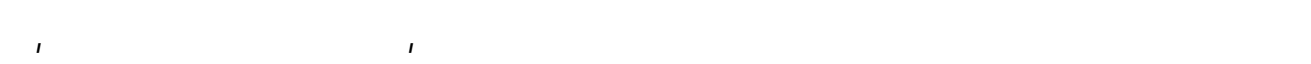

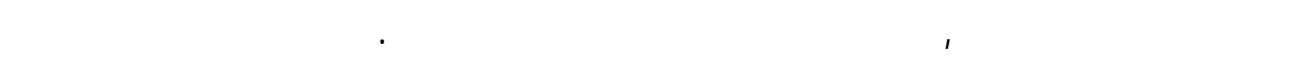
الجلمعي في الترتيب الأخير بالنبة لمجالات ققيم مستوى أداء أعضاء هيئة التدربيس بقهم الاقتصاد المززلي بكلية التربية النوعية جلمعة المنوفية، حيث جاءت بمتوسط هسابي بلغ

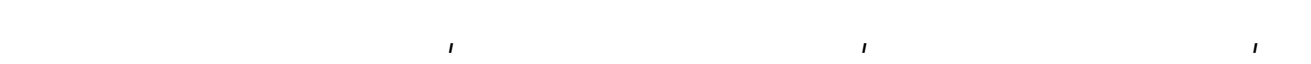
متوسطة. وللشكل البياني التالي يوضح درجة ققيم الطلاب لأعضاء هيئة التدريس بقم الاقتصاد المذزلي بكلية التربية الذوعية جلمعة المذوفية

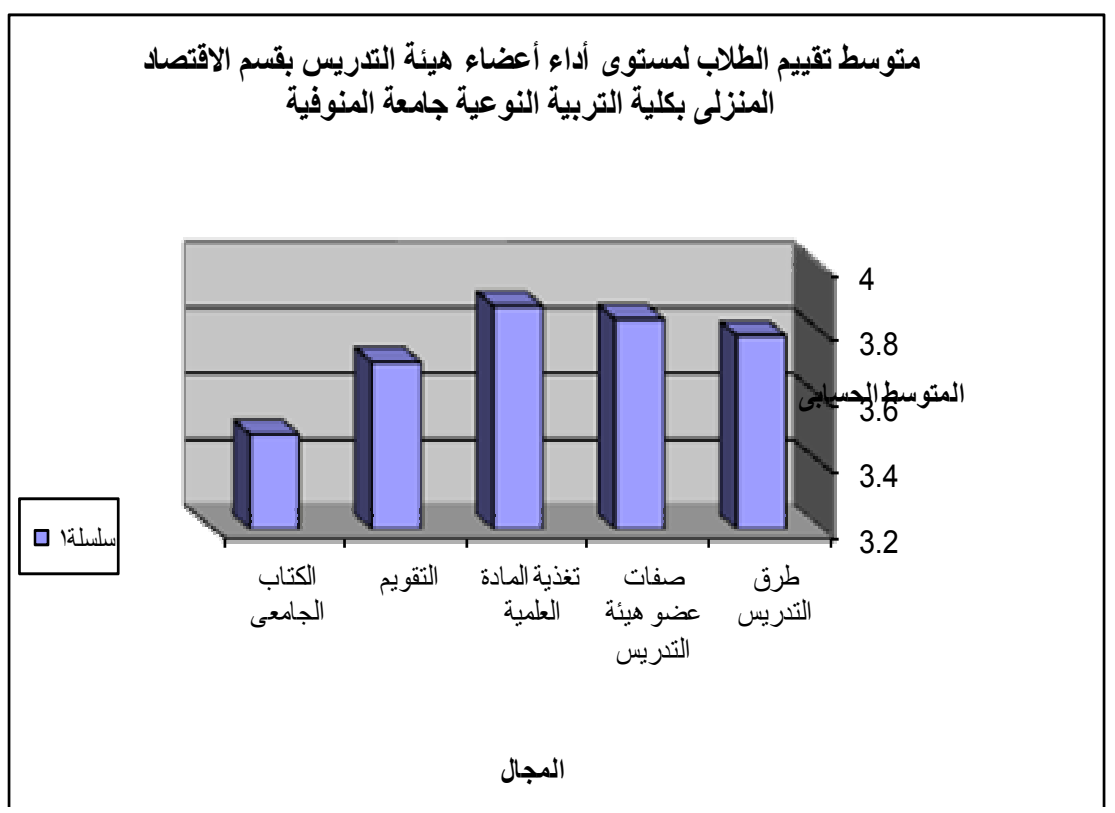




\section{| -فيما يتعاق بمجلطرق التربس المستخمة:}

يبين الجدول التالي قيمة "ت" لدلالة الفروق بين المتوسطلت الحسابية والمتوسط الاعتباري لدرجة لستجابلت مفردات عينة الدرلسة منطلابشعبة الاقتصاد المذزلي على مجل طرق التدربيس المستخمة كلحد جوالب ققيم عضو هيئة التدربيس بقم الاقتصاد المذزلي بكليلت التربية النوعية.

\section{(r) (1)}

يوضحقيمة "ت" لدلالة الفروق بين المتوطملت الهسلبية والمتوطما لاعتباري لدرجة قيم

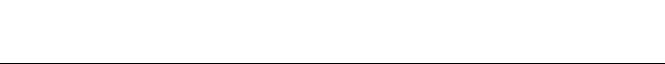

\begin{tabular}{|c|c|c|c|c|c|c|c|c|c|c|c|c|}
\hline القييمة & الترتيب & النسب & الدسالة & "تّ" & المعناري & المتوبط & معارض & معارض & محليد & مولق & بشوة: & العبارة \\
\hline مرفع & 1 & $\wedge 1$, & دالة*** & $11, \cdot \varepsilon$ & " & $\varepsilon, \cdot 0$ & $r$ & $\mu$ & $\mu$ & દ૧ & 19 & 1 \\
\hline مرفقع & 0 & $\mathrm{~V} \varepsilon, \varepsilon$ & دالة & $7, \varepsilon \Lambda$ & $\cdot, 9 \mathrm{~V}$ & $\mu, V r$ & $\varepsilon$ & $\varepsilon$ & $1 \%$ & ع & Ir & $r$ \\
\hline مررفع & $\mu$ & $\mathrm{V} 7,1$ & دالة *** & $v, \cdot 0$ & $1, r$ & $\mu, \Lambda \mu$ & 0 & 1 & $1 \varepsilon$ & " & 11 & $\boldsymbol{r}$ \\
\hline مرنقع & $\mu$ & $\mathrm{V} 7,7$ & دالة & $7, \varepsilon \mu$ & $1,1 r$ & $\mu, \Lambda \mu$ & 0 & $r$ & 19 & ro & ro & $\varepsilon$ \\
\hline مرثفع & 7 & $v^{\mu}, 7$ & دالة & $\varepsilon, \Lambda \mu$ & $1, r \varepsilon$ & $\mu, 7 \Lambda$ & v & 7 & $1 \%$ & ru & זr & 0 \\
\hline مرثفع & $r$ & $\mathrm{VV}, \varepsilon$ & دالة & $7,7 V$ & $1,1 \varepsilon$ & $\mu, \Lambda V$ & 0 & $\varepsilon$ & Ir & $\mu$. & ro & 7 \\
\hline مرفعع & $\varepsilon$ & VO, $\Lambda$ & دالة & $7, \Upsilon\urcorner$ & $1,1$. & ऍ,V१ & $\varepsilon$ & 0 & 17 & rq & r & $\mathbf{v}$ \\
\hline مرفعع & $\varepsilon$ & $\mathrm{V} 0, \Lambda$ & دالة *** & $0, \Lambda \mu$ & 1,11 & r,vq & v & $\mu$ & 11 & س山 & r & $\boldsymbol{\Lambda}$ \\
\hline مرقفع & 0 & $\mathrm{~V} \varepsilon, \varepsilon$ & دالة*** & $0, \mathrm{r \Lambda}$ & $1, r$ & $\mu, v r$ & $\varepsilon$ & 9 & 17 & זr & ro & 9 \\
\hline متوطط & V & $v r, \Lambda$ & دالة *** & $0,7 \Lambda$ & $\cdot, 99$ & $\mu,\rceil \varepsilon$ & $\varepsilon$ & $\varepsilon$ & 19 & $\mu V$ & Ir & 1. \\
\hline مرفع & - & $V r, \Lambda$ & |لاعتبارى & المتو & $1, \cdot 1$ & щ,vq & & & & & & الملى \\
\hline
\end{tabular}

يتضح من الجدول للسابق أن ققيم أداء أعضاء هيئة التدربس بأقنس الاقتصاد المذزلي من وجهة ظار الطلاب فيما يتعلق بمجل طرق التدريس المستخمة حصل على درجة تقدير (مرقعة)، بينما حصلت عبارات هذا المجل على درجة تقدير تراومت بين مرتقعة ومتوسطة، وكالت أعلى هذه العبارات ترتيبا هي مشكلة " تساعدطريقة التدربيس على تحقيق الأهداف للسلوكية " حيث حصلت على درجة ققدير مرتفعة بمتوطط هسابي 0 ·,ع

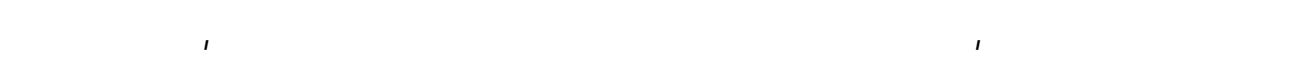
فروق ذات دلالة إحصائية عند مستوى ا..,. بين المتوطط المسابي لهذه العبارة والمتوسط الاعتباري لصالح المتوط الحسابي حيث بلغت قيمة "ت" ع.,11، وجاء في 
الترتيب التالي بدرجة ققدير مرتقعة أيضاً عبارة " تتبح فرصة للعل الفردي والعهل

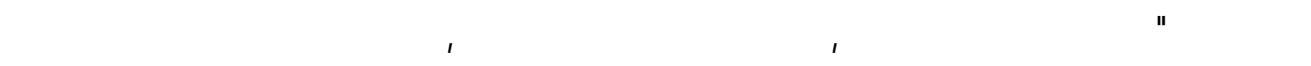
النبي الني بلغت ع,VV ، ووجدت فروق ذات دلالة إحصائية عند مستوى ا ·., بين المتوسط الحسابي لهذه العبارة والمتوسط الاعتبارى لصالح المتوطط الحسابي، حيث بلغت

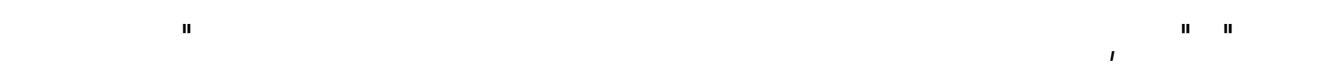

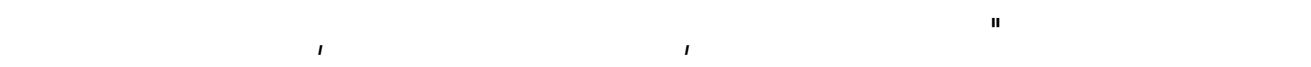
الوزن النسب الني بلغت V7,7 ، ووجدت فروق ذات دلالة إحصائية عند مستوى ا . ., ال. بين المتوسط العسابي لهذ العبارة والمتوطط الاعتبارى لصالح المتوط المسابي، حيث

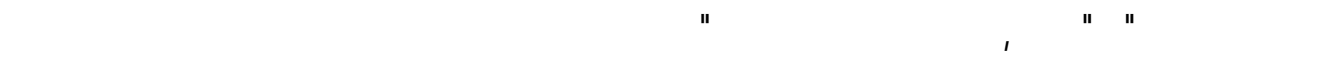
الموقف التعليمي " في الترتيب الأخير بدرجة نقدير متوسطة بمتوطط هسابي بلغت قيمته

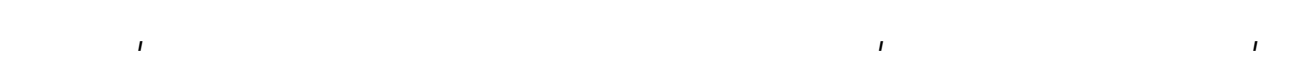
وجدت فروق ذات دلالة إحصائية عند مستوى I · , · بين المتوط الهسابي لهذه العبارة والمتوطط الاعتبارى لصالح المتوط المسابي، حيث بلغت قيمة "ت" 0,74. كما يتضح من خلل الجدول للسابق أن المتوسط العسابي لإجابلت أفراد عينة الطلاب

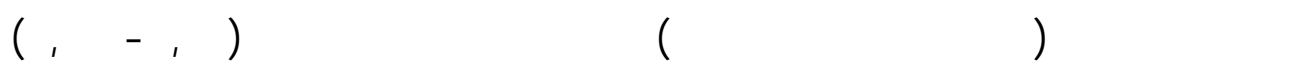

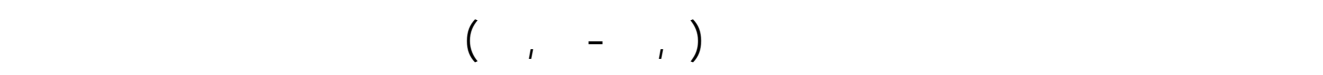

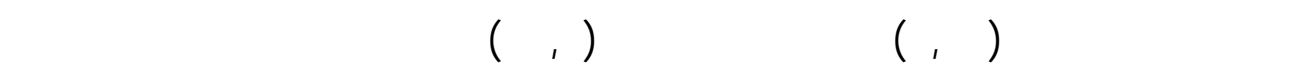
طررق التدريس المستخمة لكبرمن المتوط الهسابي الفرضي الذي كان (س) وبوزن شسبى

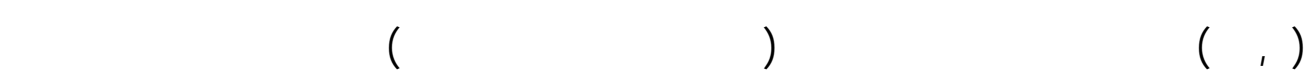
قم ققدير لستخدل أعضاء هيئة التدربيس لطرق التدريب فاعلية من وجهة ظقر الطلاب حيث مق ققدر هذا الإستخدلم بدرجة مرتقعة ، وهو ما يدل على أن أعضاء هيئة التدريس بقم الاقتصاد المذزلي بكلية التربية النوعية جلمعة المنوفية يستخمونطورق التدربيس فاعلية ومهارة تتبح للطلاب اللسقاة الكلملة من أعضاء هيئة التدريس. 


\section{م -فيما يتهاق بمجل صفلت عضو هيئة التربس:}

يبين الجدول التالي قيمة "ت" لدلالة الفروق بين المتوططلت المسابية والمتوطط الاعتباري لدرجة لستجابلت مفردات عينة الدرلسة منطلابشعبة الاقتصاد المذزلي على مجل صفلت عضو هيئة التدربيس كلحد جوالب ققيم عضو هيئة التدربيس بقم الاقتصاد المذزلي بكليت التربية النوعية.

\section{جط (r)}

يوضحقيمة "ت" لدلالة الفروق بين المتوطلت الهسلبية والمتوطما لاعتباري لدرجة قيميم مفردك الهينة المجل صفلت عضو هيئة التربيس

\begin{tabular}{|c|c|c|c|c|c|c|c|c|c|c|c|c|}
\hline القيمة & الترتيب & النسبي & الدسلة & "ت" " قة & المعياري & المسابل & معارضة & معارض & محليد & موايق & بمولقة & العبارة \\
\hline مرقفع & 1 & $\Lambda r, r$. & دالة *** & $\Lambda, \bigvee \varepsilon$ & $1,1$. & $\varepsilon, 1)$ & $\mu$ & $\varepsilon$ & r & $r$. & $\mu V$ & 1 \\
\hline مرقع & 0 & v१, . & دالة*** & $\mathrm{V}, \mathrm{\mu q}$ & $1,1 r$ & $r, 90$ & $r$ & $\Lambda$ & $1 \mu$ & ז & ו" & $\boldsymbol{r}$ \\
\hline مرقع & $r$ & $\wedge 1,7$. & دالة & १,७V & $\cdot, 97$ & $\varepsilon, \cdot \Lambda$ & 1 & 0 & 11 & rq & $\mu$. & $\boldsymbol{r}$ \\
\hline مرقفع & 11 & $V \varepsilon, r$. & دالة**** & $\varepsilon, \vee १$ & $1, r q$ & $\mu, V)$ & V & V & $1 \varepsilon$ & ו & rV & $\varepsilon$ \\
\hline متوسط & $1 \mu$ & vi,. & دالة**** & $\varepsilon, \varepsilon \mu$ & $1, \cdot 9$ & $\mu, 00$ & 0 & 0 & rE & rV & 10 & 0 \\
\hline مرقع & V & $V V, r$. & دالة & $7, \mathrm{VO}$ & 1,1 . & $\mu, \Lambda 7$ & 0 & $\mu$ & I & r" & r & 7 \\
\hline مرقفع & $\Lambda$ & vi, 7. & دالة & $7,1 \mathrm{~V}$ & $1,1 \mathrm{~V}$ & $\mu$ & $\mu$ & 1. & 11 & ro & rV & $\mathbf{v}$ \\
\hline مرقفع & $\mu$ & $\wedge 1, \cdot \cdot$ & دالة*** & $9,1 \mu$ & $1, \cdot 1$ & $\varepsilon, \cdot 0$ & 1 & 0 & 10 & سץ & r & $\boldsymbol{\Lambda}$ \\
\hline مرقفع & 7 & $V V, \varepsilon$. & دالة & V,IT & $1, \cdot 7$ & $\mu, \Lambda \vee$ & $r$ & V & 10 & rV & ro & 9 \\
\hline مرنقع & $\varepsilon$ & v१, r. & دالة**** & 9,10 & • & 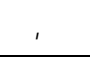 & $r$ & $\mu$ & r & $\mu \Lambda$ & וז & 1. \\
\hline مرقع & 9 & $\vee\urcorner, \varepsilon$. & دالة & $V, \cdot 9$ & $1, \cdots$ & $r, \Lambda r$ & $\mu$ & 0 & Ir & $\mu V$ & 11 & 11 \\
\hline مرتقع & 1. & $\mathrm{~V} 0, \Lambda$. & دالة**** & $0, ૧ દ$ & 1,17 & r,V१ & 0 & $\varepsilon$ & 11 & rE & ro & r \\
\hline متوسط & $1 \varepsilon$ & $79, \wedge$. & دالة & r,or & $1, r \mid$ & ץ,દ૧ & $\Lambda$ & $\varepsilon$ & $r \varepsilon$ & זי & IV & Ir \\
\hline متوسط & Ir & $V^{\mu}, r$. & دالة*** & $\varepsilon, ૧ \varepsilon$ & 1,17 & $\mu, 77$ & 7 & $r$ & רז & $r$. & זr & $1 \varepsilon$ \\
\hline مرقفع & $\varepsilon$ & v१, r. & دالة**** & १, & $\cdot, \Lambda \mathrm{V}$ & r, १७ & . & 0 & 10 & & r & 10 \\
\hline مرفع & - & vา,१ & 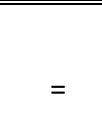 & & $1, \cdot 1$ & $\mu, \wedge \varepsilon$ & & & & & & المل \\
\hline
\end{tabular}

يتضح من الجدول للسابق أن نقيم أداء أعضاء هيئة التدريس بأقنسم الاقتصاد المززلي من وجهة ظر الطلاب فيما يتعلق بمجل صفلت عضو هيئة التدربيس حصل على درجة تقدير (مرقعة)، بينما حصلت عبارات هذا المجل على درجة ققدير تراومت بين مرقفعة

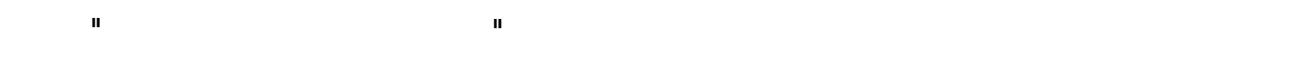

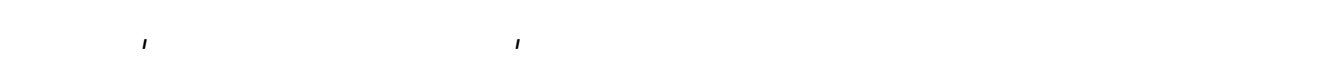


ما يؤكه قيمة الوزن النسبي التي بلغت · r, بr، ووجدت فروق ذات دلالة إحصائية عند مستوى I .., بين المتوطط الهسابي لهذه العبارة والمتوطط الاعتبارى لصالح المتوطط التسابي حيث بلغت قيمة "ت" ع,_,V، وجاء في الترتيب التالي بدرجة نقدير مرتفعة أيضاً

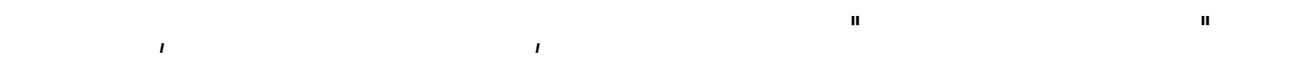

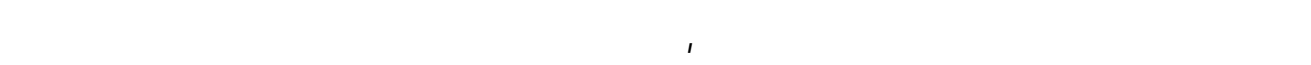
مستوى I ·., بين المتوطط الهسابي لهذه العبارة والمتوطط الاعتبارى لصالح المتوطط

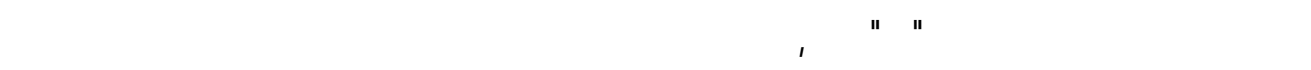

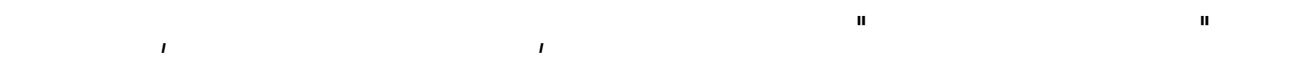
يؤككه قيمة الوزن النسب التي بلغت ·,ای،، ووجدت فروق ذات دلالة إحصائية عند مستوى I .., بين المتوطط الهسابي لهذه العبارة والمتوطط الاعتبارى لصالح المتوطط

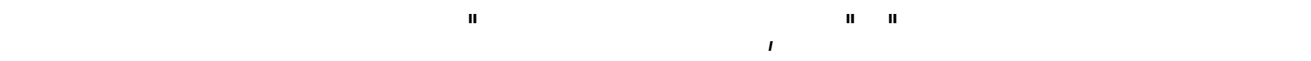

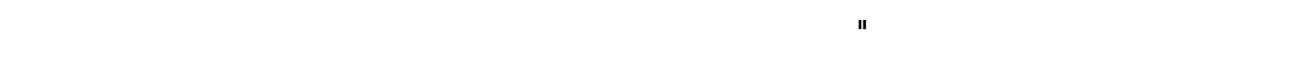

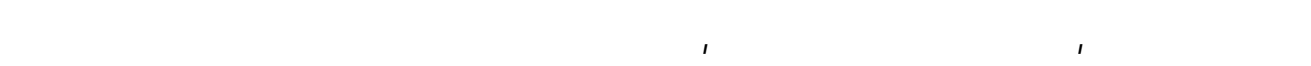

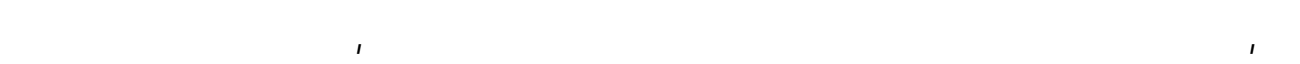

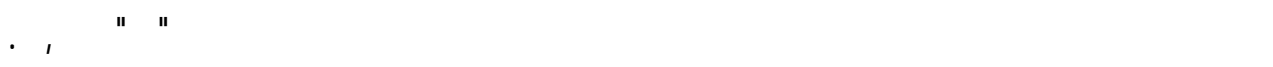

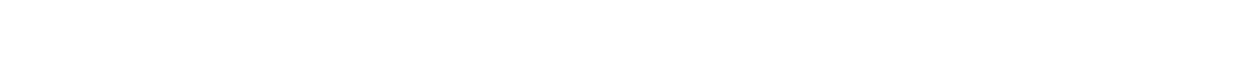

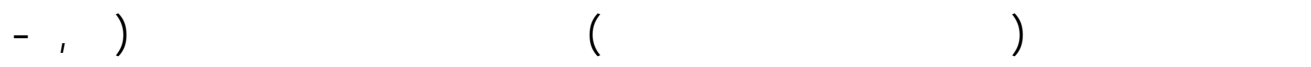

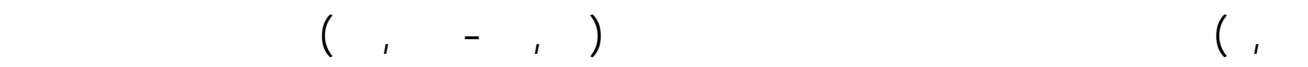

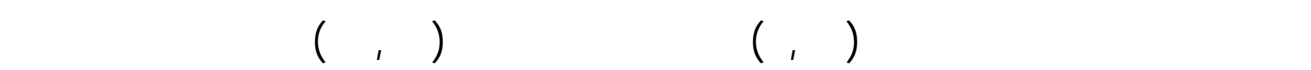

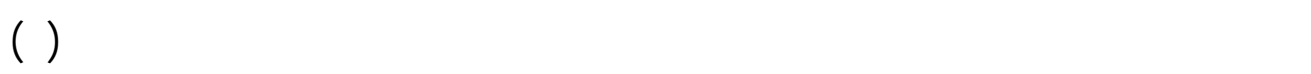

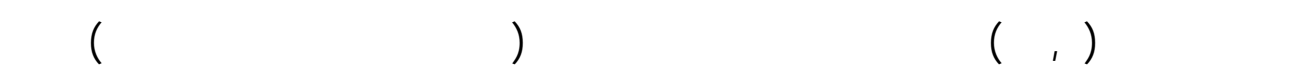
بحلجة إلى تعدل فقد مق ققدير صفلت أعضاء هيئة التدربيس من وجهة ظقر الطاللاب بدرجة

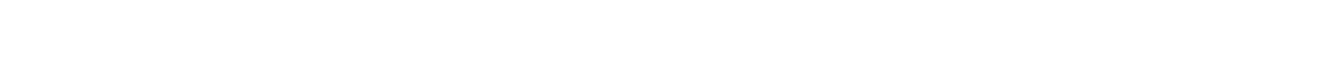
النوعية جلمعة المذوفية يتصفون بالمهارة والجة والإللاع والصفلت التي تليق بعضو هيئة

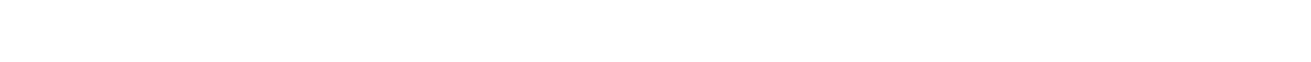
مثلا وقدوة يحتذي بها من جانب الطلاب. 


\section{ع -فيما يتهاق بمجلطرقة تخنية الماة العامية:}

يبين الجدول التالي قيمة "ت" لدلالة الفروق بين المتوططت المسابية والمتوطط الاعتباري لدرجة لستجابلت مفردات عينة الدرلسة منطلابشعبة الاقتصاد المذزلي على فيله مجل طريقة تغذية المادة العلمية كلحد جوافب قفيم عضو هيئة التدربيس بقم الاقتصاد

\section{جرط (ع)} المذزلي بكليت التربية النوعية.

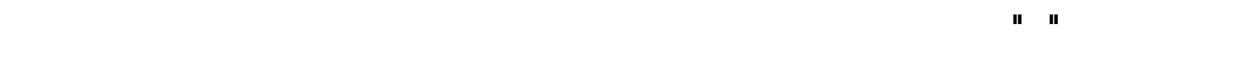

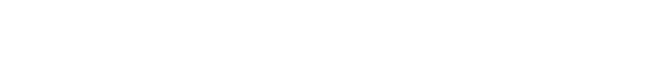

\begin{tabular}{|c|c|c|c|c|c|c|c|c|c|c|c|c|}
\hline القرجيم & الترتيب & النسبي & الدسالة & "قت" & المعياري & المتوبط & معارضة & معارض & محليد & مولق & بشوائة & المبأرة \\
\hline مرقفع & 1 & $\Delta r, r$. & دالة *** & $\Lambda, \vee \varepsilon$ & $1,1$. & $\varepsilon, 1)$ & $\mu$ & $\varepsilon$ & Ir & $r$. & $\mu V$ & 1 \\
\hline مرقع & $\mu$ & จ१, * & دالة *** & $v, \mu q$ & I,Ir & ץ, १० & $r$ & $\wedge$ & $1 \%$ & זr & I & $r$ \\
\hline مرقع & $r$ & $\wedge 1,7$. & دالة *** & १,VV & $\cdot, 97$ & $\varepsilon, \cdot \Lambda$ & 1 & 0 & 11 & rq & $\mu$. & $\boldsymbol{\mu}$ \\
\hline مرقعع & 0 & $V \varepsilon, r$. & دالة *** & $\varepsilon, \vee १$ & 1,rq & $\mu, \mathrm{VI}$ & V & V & $1 \varepsilon$ & r & rV & $\varepsilon$ \\
\hline متوبط & 7 & vI, $\cdot$ & دالة *** & $\varepsilon, \varepsilon \mu$ & $1, \cdot 9$ & $\mu, 00$ & 0 & 0 & $r \varepsilon$ & rV & 10 & 0 \\
\hline مرتفع & $\varepsilon$ & $v V, r$. & دالة *** & $7, \mathrm{~V} 0$ & $1,1$. & $\uparrow, \Lambda\rceil$ & 0 & $\mu$ & $1 \%$ & r & r & 7 \\
\hline مرفع & - & VV,OH & $\begin{array}{r}r \\
r=5\end{array}$ & & 1,11 & $\mu, \Lambda \Lambda$ & & & & & & اكلم لـل \\
\hline
\end{tabular}

يتضح من الجدول السابق أن قِيم أداء أعضاء هيئة التدريس بأقتسلم الاقتصاد المنزلي من وجهة ظر الطلاب فيما يتعلق بمجل طريقة تغنية المادة العلمية حصل على درجة

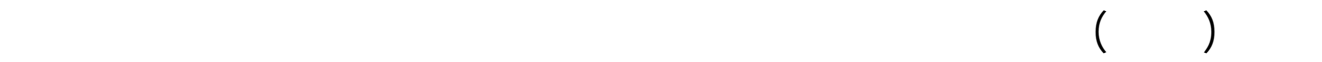

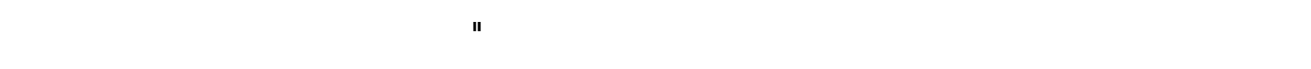

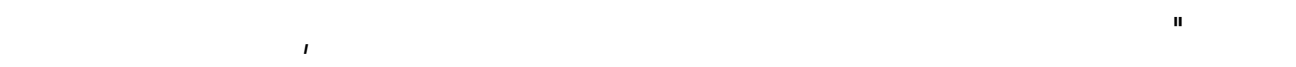

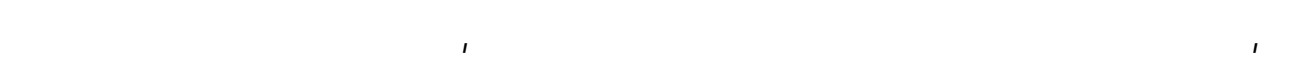
إحصائية عند مستوى ا ·.,. بين المتوط المسابي لهذه العبارة والمتوسط الاعتبارى

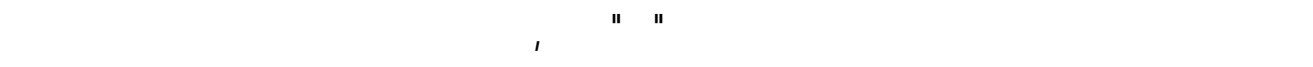
تقدير مرتفعة أيضاً عبارة" يربط المعلوملت الظرية بالظبيقات العملية " بمتوسط هسابي

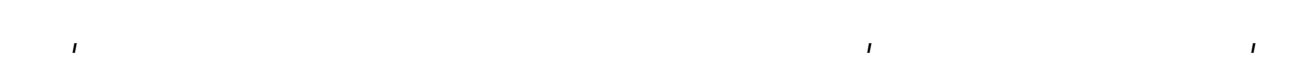


ووجدت فروق ذات دلالة إحصائية عندمستوى I · , · بين المتوطط المسابي لهذه العبارة

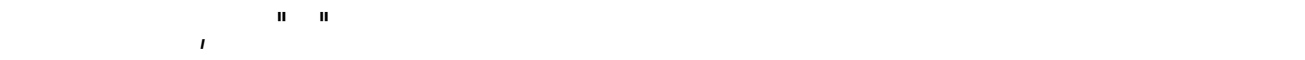

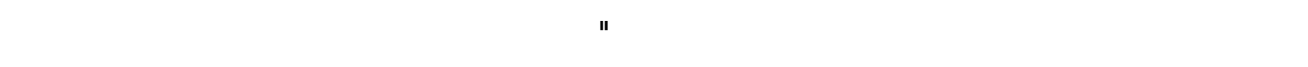

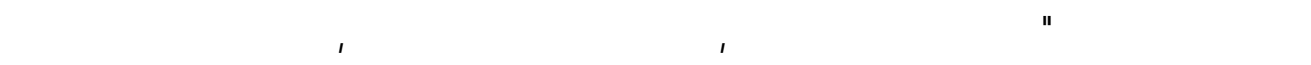

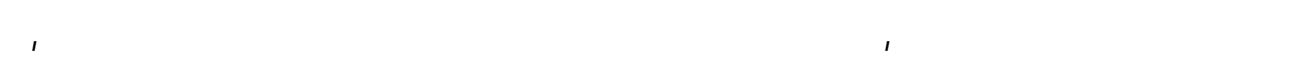
بين المتوطط الهسابي لهذه العبارة والمتوسط الاعتبارى لصالح المتوط الهسابي، حيث

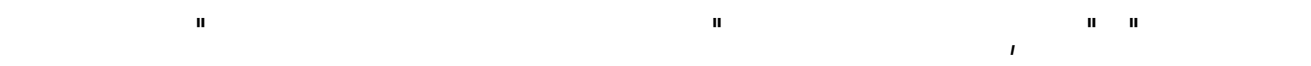

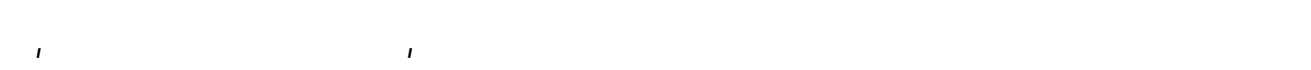

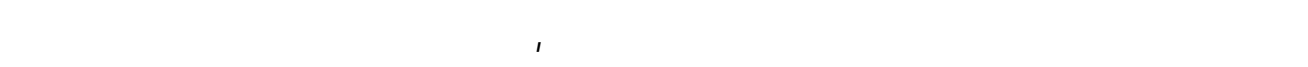
إحصائية عند مستوى ا ·., بين المتوطط المسابي لهذه العبارة والمتوسط الاعتبارى لصالح المتوسط الهسابي، حيث بلغت قيمة "ت" بعرع.ع. كما يتضح من خلل الجدول للسابق أن المتوسط العسابي لإجابلت أفراد عينة الطلاب

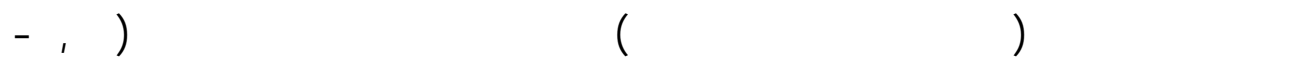

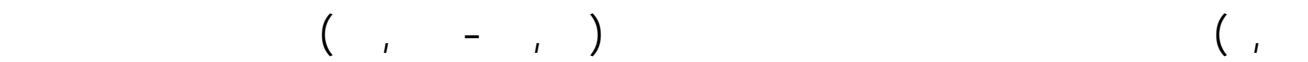
الفرضي المرجح للمجل كل (

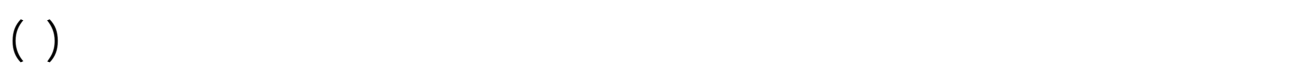

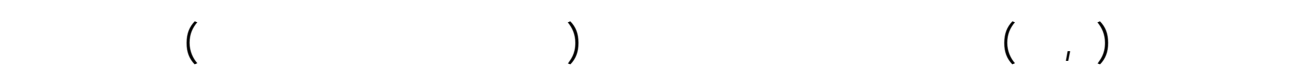

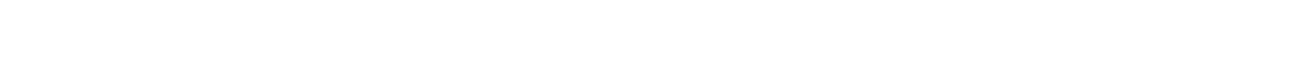
وهو ما يدل على أن أعضاء هيئة التدريس بقم الاقتصاد المذزلي بكلية التربية النوعية جلمعة المذوفية يتصفون بالمهارة في لستخدلمطرق تغذية المادة العلمية الأمر الذي يطل إلى حد رضا الطلاب عن المحتوى الذي ينالقونه.

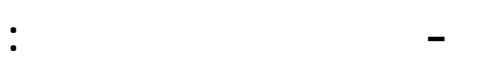

يبين الجدول التالي قيمة "ت" لدلالة الفروق بين المتوططلت المسابية والمتوطط الاعتباري لدرجة لستجابلت مفردات عينة الدرلسة منطلابشعبة الاقتصاد المذزلي على فيله مجل القويم كلحد جوانب ققيم عضو هيئة التدريس بقم الإتصاد المنزلي بكليت التربية النوعية. 


\section{(0) (0) (0)}

يوضحقيمة "ت" لدلالة الفرق بين المتوطلت الهسلبية والمتوطط الاعتباري لرجة ققيم

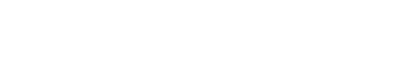

\begin{tabular}{|c|c|c|c|c|c|c|c|c|c|c|c|c|}
\hline القيجمة & النرتيب & النسبي & الدلآلة & "ت" " & المعياري & المسكب & معارض & معارض & محليد & موايق & موليق & العبأرة \\
\hline مرقفع & $\mu$ & $\mathrm{v} 7, \cdot 0$ & دالة *** & T, Tr & 1,11 & ${ }^{\mu}, \Lambda$. & 0 & $\mu$ & 17 & $\mu$. & r & 1 \\
\hline متوسط & 11 & $\mathrm{~V} 1,0 \wedge$ & دالة *** & $\varepsilon, \vee O$ & $1, \cdot 7$ & $\mu, 0 \wedge$ & V & $\mu$ & $1 \varepsilon$ & عॉ & 9 & $r$ \\
\hline مرقعع & $\Lambda$ & $V^{\mu}, 90$ & دالة**** & $0, \Lambda 1$ & 1,0 & $\mu, v$. & $\varepsilon$ & 7 & $1 \varepsilon$ & rv & 10 & $\boldsymbol{r}$ \\
\hline مررقع & V & $V \varepsilon, Y I$ & دالة *** & ع ع & $\cdot, 9 \wedge$ & $\mu, \mathrm{VI}$ & $\mu$ & $\varepsilon$ & $r$. & & 10 & $\varepsilon$ \\
\hline مرثقع & 1 & $V V, \wedge ৭$ & دالة*** & $\mathrm{V}, \mathrm{q}$. & $\cdot, १ ९$ & $\stackrel{\sim}{ }{ }^{\wedge} \wedge$ & 1 & 0 & $r$. & ro & ro & 0 \\
\hline مرثقع & 7 & vo,rר & دالة*** & $0, \mathrm{VV}$ & 1,10 & $\stackrel{\mu}{\mathrm{V}, \mathrm{\urcorner}}$ & 7 & $r$ & 19 & $r 7$ & r & 7 \\
\hline مرقفع & $r$ & $V V, \mu V$ & دالة**** & $\mathrm{V}, \mathrm{\mu q}$ & $1, r$ & ${ }^{\mu}, \Lambda \vee$ & $\mu$ & $\varepsilon$ & 10 & זr & r & $\mathbf{v}$ \\
\hline مرفقع & $\varepsilon$ & $\mathrm{V}\urcorner, 0 \wedge$ & دالة & $\mathrm{V}, \cdot 0$ & $1, \cdot r$ & $\mu$ & $\varepsilon$ & $r$ & IV & $\mu \mu$ & $r$. & $\boldsymbol{\Lambda}$ \\
\hline مرتفع & 9 & $V^{\mu}, \varepsilon r$ & دالة *** & $0, \Lambda 7$ & $1, \cdots$ & $\mu, 7 V$ & $\mu$ & 0 & r & ז" & 10 & 9 \\
\hline مرقع & 0 & vo,vq & دالة*** & $7, \varepsilon$. & $1, \cdot V$ & ґ, (१ & 0 & $r$ & IV & r & $r$. & 1. \\
\hline متوسط & 1. & $\vee \backslash, \wedge \varepsilon$ & دالة*** & $\varepsilon, \varepsilon\rceil$ & 1,17 & ऍ,0१ & 7 & V & 10 & r & 17 & 11 \\
\hline متوسط & Ir & rT, & * دالة & $r, 1$. & $||,, \mid$ & ז", & 1. & 11 & 10 & ro & 10 & Ir \\
\hline مرفع & - & $V \varepsilon, 19$ & r r تبلبرى & |المتوطط | & $1, \cdot 1$ & ${ }^{\mu}, \mathrm{VI}$ & & & & & & المجل \\
\hline
\end{tabular}

يتضح من الجدول للسابق أن ققيم أداء أعضاء هيئة التدربيس بأقتسل الاقتصاد المذزلي من وجهة ظار الطلاب فيما يتعلق بمجل القويم حصل على درجة ققدير (مرتفعة)، بينما حصلت عبارات هذا المجل على درجة ققير تراومت بين مررقعة ومتوسطة، وكافت أعلى هذه العبارات ترتيبا هي عبارة " عملية القومي عملية مستمرة" حيث حصلت على

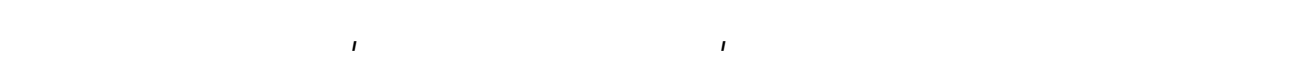
الوزن النسب الني بلغت بين المتوسط المسابي لهذه العبارة والمتوطط الاعتبارى لصالح المتوطط العسابي حيث

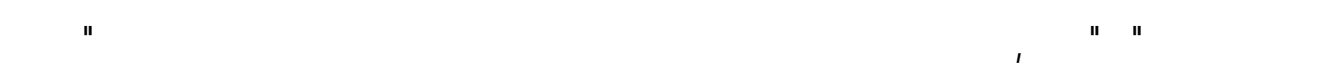

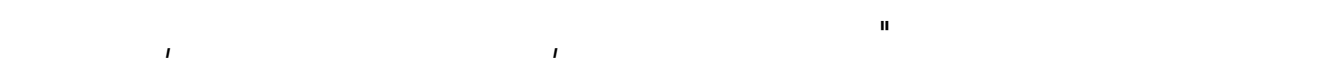

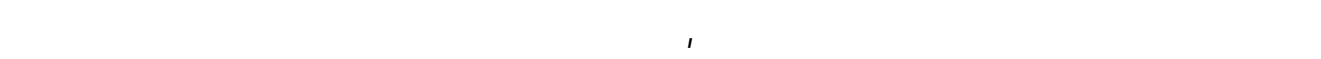
مستوى I . , . بين المتوطط الحسابي لهذه العبارة والمتوطط الاعتبارى لصالح المتوط

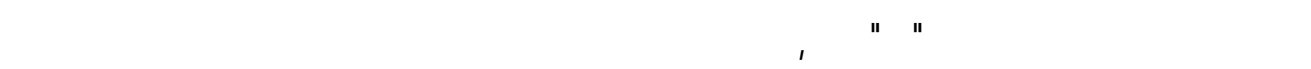


عبارة " يتناول القويم جميع جوافب الأهداف التعليمية التي م صياغتها " بمتوطط هسابي

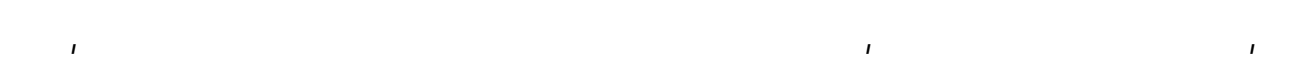
ووجدت فروق ذات دلالة إحصائية عند مستوى I · ·, ب بين المتوطط المسابي لهذه العبارة والمتوسط الاعتبارى لصالح المتوطط الهسابي، حيث بلغت قيمة "ت" بّب,7، وجاءت عبارة " يراعى الفروق الفردية بين الطلاب" في الترتيب الأخير بدرجة ققدير متوسطة

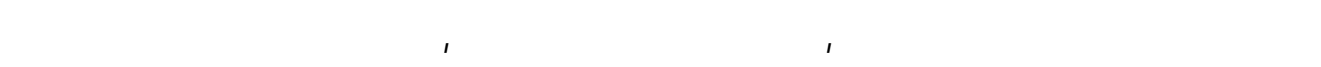
النسبي الني بلغت كَ,77، كما وجدت فروق ذات دلالة إحصائية عند مستوى 0 ·, · بين المتوسط الهسابي لهذه العبارة والمتوطط الاعتبارى لصالح المتوطط المسابي، حيث بلغت

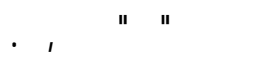

كما يتضح من خلل الجدول للسابق أن المتوط الهسابي لإجابلت أفراد عينة الطلاب

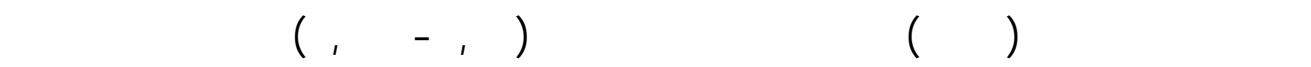

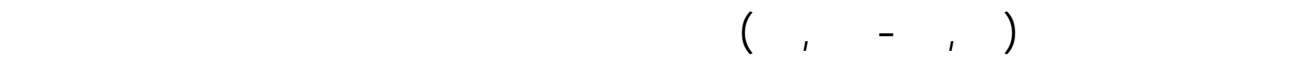

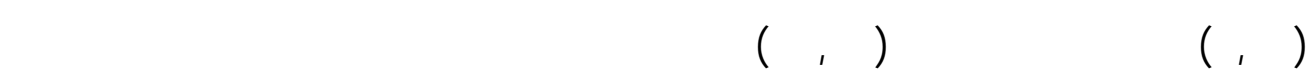

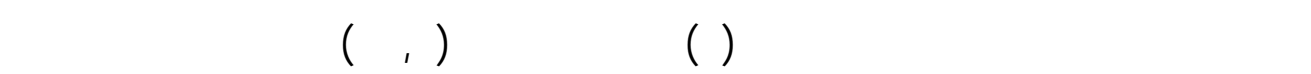

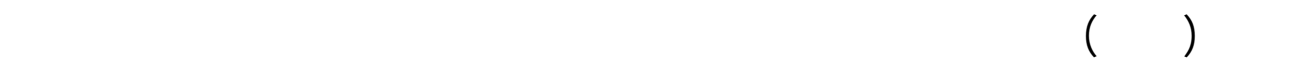
بدرجة مرتفعة، وهو ما يال على أن أعضاء هيئة التدربيس بقم الاقتصاد المذزلي بكلية التربية الزوعية جلمعة المنوفية يتصفون بالمهارة في لستخدلمطرق النقويم المختلفة ويدل على ذلك مستوى تقيم الطلاب لطرق القيم المختلفة لأعضاء هيئة التدربيس حيث مم القيم من جالب الطلاب بدرجة مرتقعة.

\section{0 -فيما يتهاق بمجل الكتلب الجاهمي:}

يبين الجدول التالي قيمة "ت" لدلالة الفروق بين المتوطلت المسابية والمتوطط

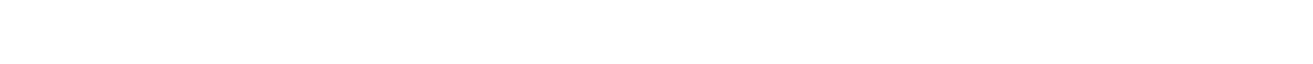
مجل الكتلب الجلمعي كلححد جوافب ققيم عضو هيئة التدربيس بقم الاقتصاد المذزلي بكليت التربية النوعية. 


\section{(7) (1) (1) (1)}

يوضحقيمة "ت" لدلالة الفروق بين المتوسطلت الهسلبية والمتوطط الاعتباري لرجة قيميم مفردك العينة المجل الكتلب الجامية

\begin{tabular}{|c|c|c|c|c|c|c|c|c|c|c|c|c|}
\hline القريمة & الترتيب & النسبي & مسنولة & "قت" & المعياري & المتوبل & معارضة & معارض & محليد & موأق & مولشة & العبارة \\
\hline متوسط & $r$ & $\mathrm{Vr}, \wedge \mathrm{q}$ & دالة*** & $\varepsilon, r \Lambda$ & $\left(,{ }^{\mu} \mid\right.$ & $\mu,\rceil \varepsilon$ & 9 & $\varepsilon$ & IV & ו & ro & 1 \\
\hline متوسط & $\varepsilon$ & $\mathrm{V} \cdot, \mathrm{OH}$ & دالة *** & ${ }^{\mu}, \Lambda \Lambda$ & 1,11 & & V & 7 & 19 & ru & 17 & $r$ \\
\hline مرغعع & 1 & $V^{\mu}, 7 \Lambda$ & دالة *** & 0,07 & $\mathrm{I}, \mathrm{V}$ & $\mu,\rceil \Lambda$ & $r$ & 1. & IV & r & 19 & $\boldsymbol{r}$ \\
\hline متوبط & 7 & $77, \cdot 0$ & دالة & $r, \varepsilon \mid$ & $1,1$. & $\mu, \mu$. & 0 & r & rE & ro & 1. & $\varepsilon$ \\
\hline متوسط & V & $7 \varepsilon, r)$ & غير دالة & $1, \mu 0$ & $1, \mu\rceil$ & $\mu, r \mid$ & Ir & 1. & I & 17 & IV & 0 \\
\hline متوسط & 0 & $7 \wedge, 90$ & دالة_** & $\mu, 0 \varepsilon$ & $1,1$. & $\mu, \varepsilon 0$ & V & 0 & r) & سب & 1. & 7 \\
\hline متوسط & $\mu$ & $\vee 1, \wedge \varepsilon$ & دالة *** & $\varepsilon, 01$ & 1,10 & $\mu, 09$ & 7 & $\varepsilon$ & r & ro & 11 & $\mathbf{v}$ \\
\hline متوصطا & - & $79, \vee \varepsilon$ & تمبارى = & | المتوسط | & $1,1 \wedge$ & ץ,દ१ & & & & & & المجل \\
\hline
\end{tabular}

يتضح من الجدول للسابق أن تقيم أداء أعضاء هيئة التدريس بأقنسل الاقتصاد المنزلي من وجهة ظار الطلاب فيما يتعلق بمجل الكتلب الجلمعي حطل على درجة ققدير (متوسطة)، بينما حصلت عبارات هذا المجل على درجة ققدير تراومت بين مرتقعة ومتوسطة، وكانت أعلى هذه العبارات ترتيبا هي عبارة " يشمل الكتلب الجانب الظاري

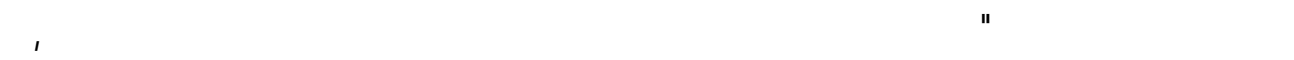

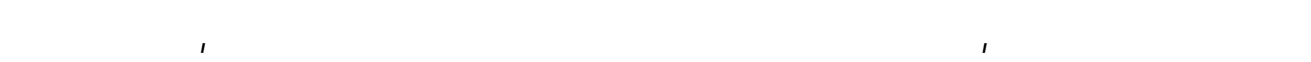
فروق ذات دلالة إحصائية عند مستوى ا..,. بين المتوطط المسابي لهذه العبارة والمتوطط الاعتبارى لصالح المتوط المسابي حيث بلغت قيمة "ت" 0,07، وجاء في الترتيب التالي بدرجة ققدير متوسطة عبارة " يهقق الكتلب تتمية الأهدف المعرفية

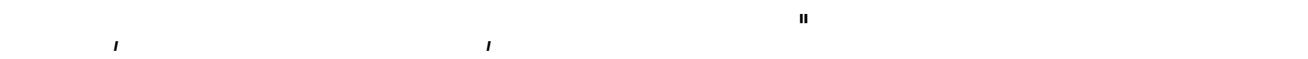
ما يؤكده قيمة الوزن النسبي التي بلغت 9 بـ,V، ووجدت فروق ذات دلالة إحصائية عند

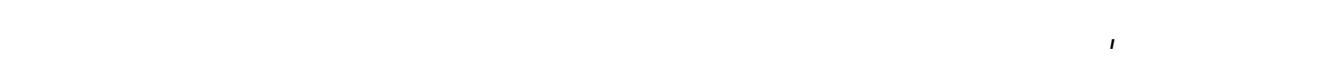
الهسابي، حيث بلغت قيمة "ت" r/,ع، وجاء في الترتيب الثالث بدرجة ققدير متوسطة

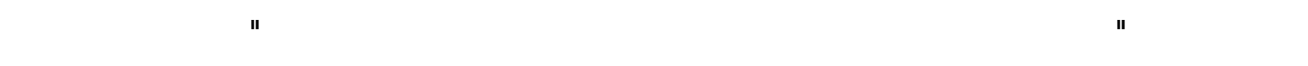

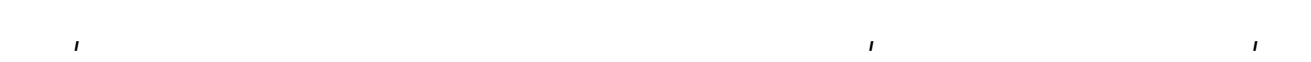
ووجدت فروق ذات دلالة إحصائية عندمستوى I · ·, · بين المتوطط المسابي لهذه العبارة 
والمتوطط الاعتبارى لصالح المتوط الهسابي، حيث بلغت قيمة "ت" أب,ع، وجاءت

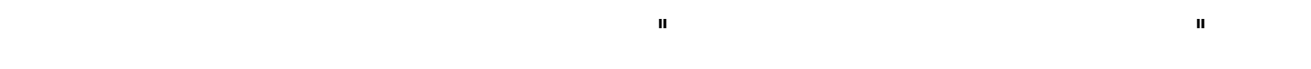

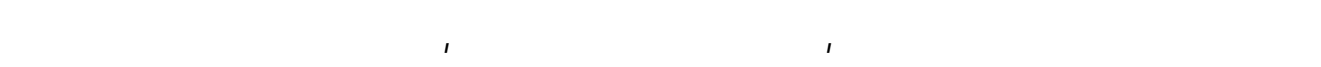
النبب التي بلغت اY,عاع، كما تبين عدم وجود فروق ذات دلالة إحصائية عند مستوى 0., · بين المتوسط الحسابي لهذه العبارة والمتوسط الاعتبارى، حيث بلغت قيمة "ت"

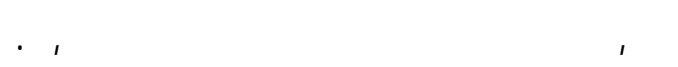
كما يتضح من خلال الجدول للسابق أن المتوسط الهسابي لإجابلت أفراد عينة الطلاب

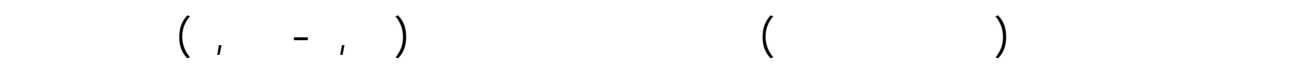

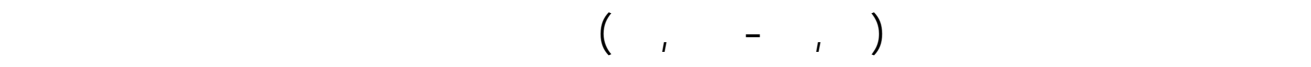

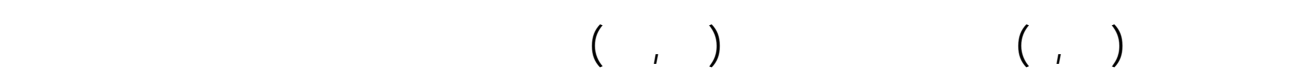

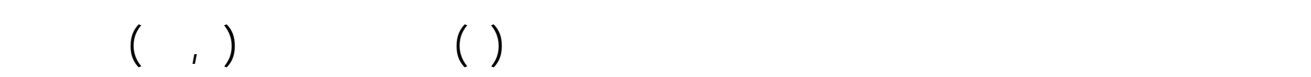

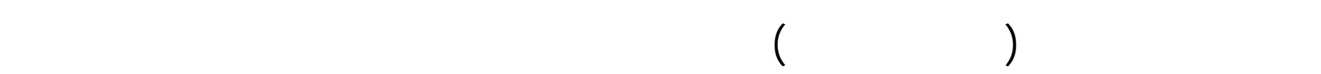

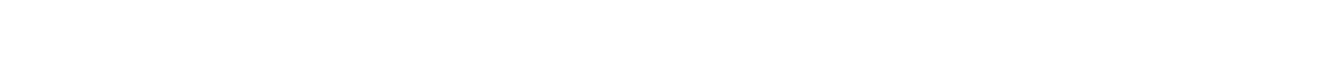

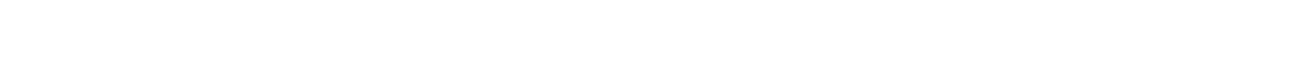

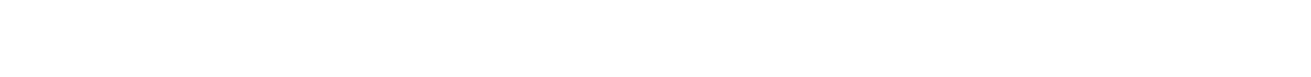
بكلية التربية النوعية جلمعة المذوفية يحرصون على توجيه الطلاب إلى المكتبلت للحصول على العلم والمعرفة ويضعون الكتلب فتط من لجل تفتبح المجالات أملم الطلاب كما ألهنه حريصين على أن يعلمون الطلاب كفي يتعلمون وكف يحصلون على المعرفة والعلم وكيفية البحث. : الفقترحك قترح البلحثة:

• إجراء درلسة حول طوير أعضاء هيئة التدريس في ضوء مطلبك الجودة اللثلملة. • لجراء درلسة نقويمية مماثلة لأعضاء هيئة التدريسي في الجلمعت الأخرى وباعتماد لأساليب مختلفة في القويم. • لجراء درلمة مقارنة بين تقوميم أعضاء هيئة التدربيس من قبل الإدارة وطلبة الدرلست العليا للوقوف على ققط القوة والضغف. 


\section{التوصيلت:}

تري البلحة اله يمكن اللمبفاة من نتائج القويم بالتوصيت التالية:

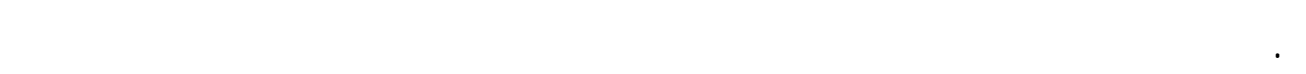

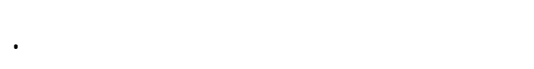
r. تدريب الطلاب وتنمية قدرالته علي عمليت القويم لضمان إعلاء نتائج تشاعد علي

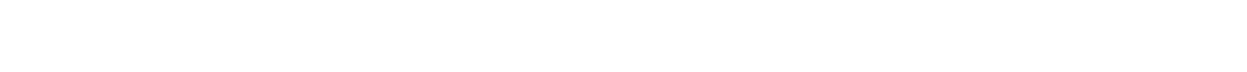

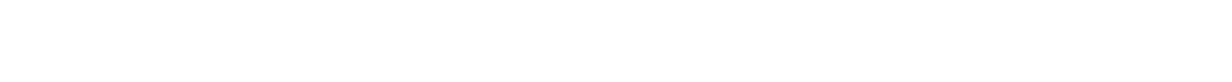

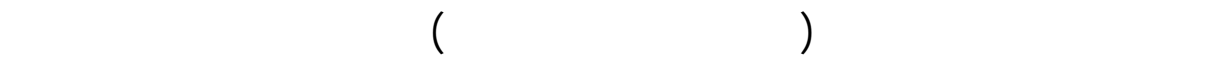
هيئة التدربي،الذي يرصد الشطط التدريسي والبهث العلم ي والنش لطا المجتمع ي اللتدريسي خلال العلم الدربلمي.

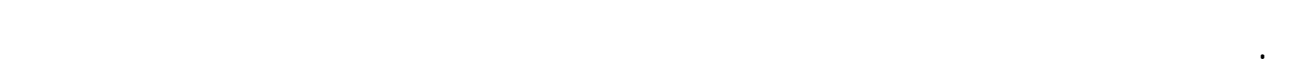

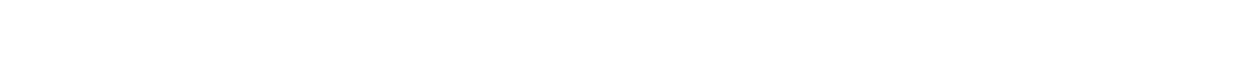

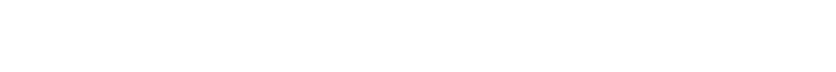

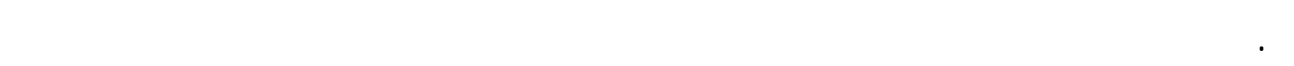
على قلط القوة والضعف مع مراعلة اللسرية في ذلك.

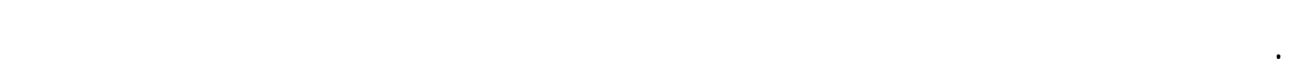
حقى يهم أعضاء هيئة التدربيس برفع قدرالتهم التدريسية.

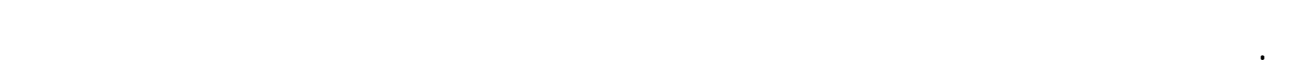

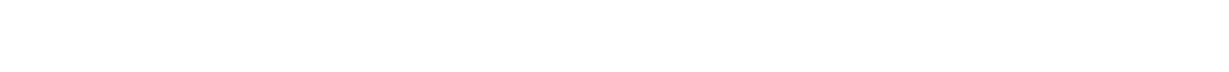
التعليم. V. تقديم حوافز مادية ومعنوية لأعضاء هيئة التدريس الجلمعي المتميزين ف في أدائه م

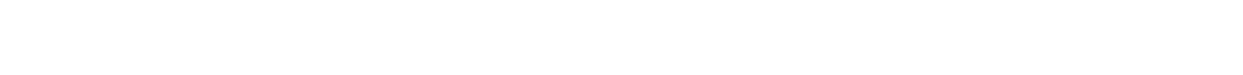

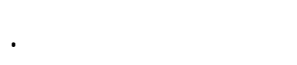




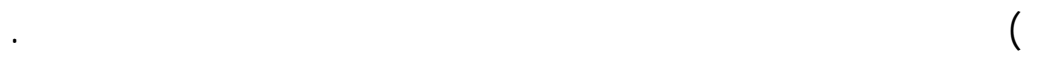

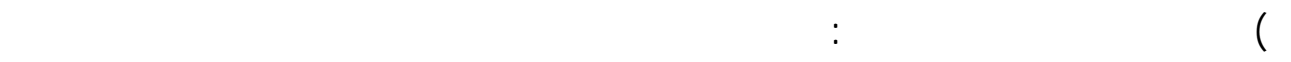

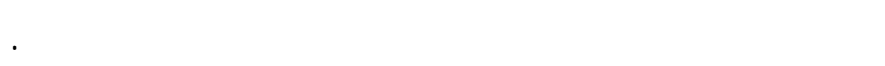

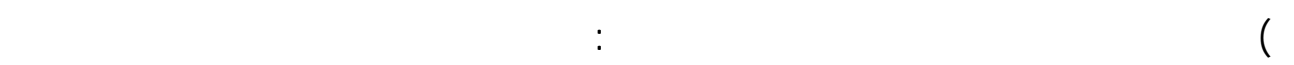

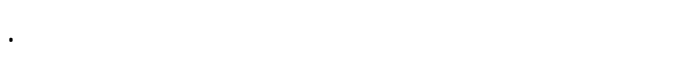

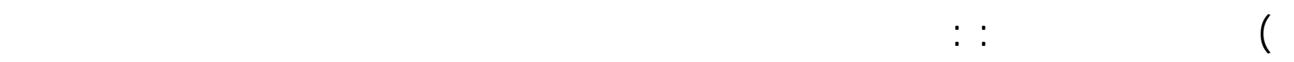

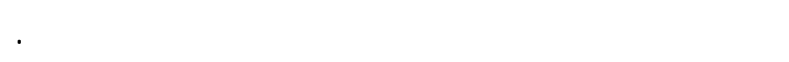

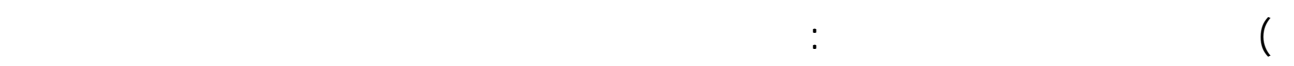

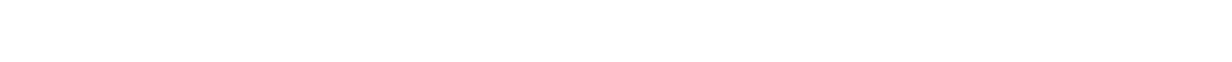

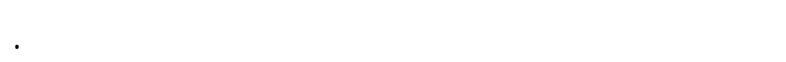

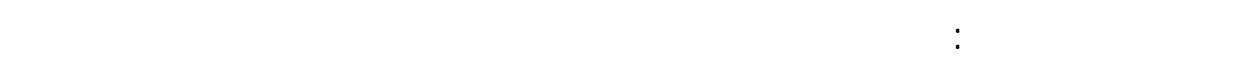

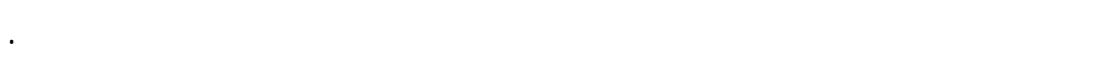

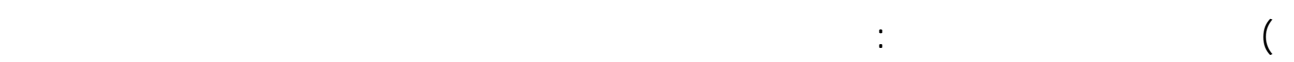

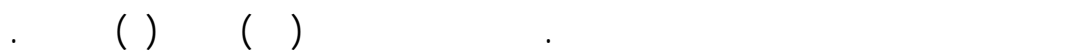

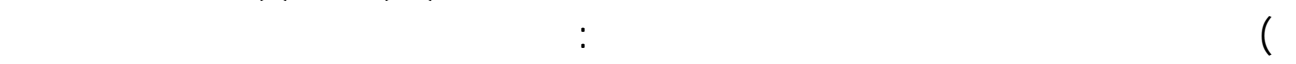

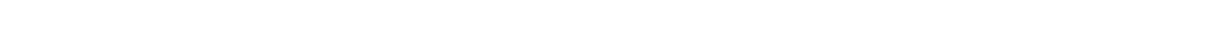

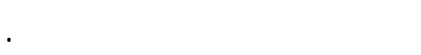

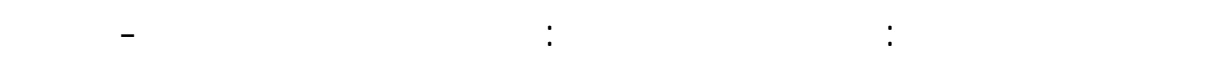

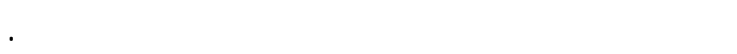

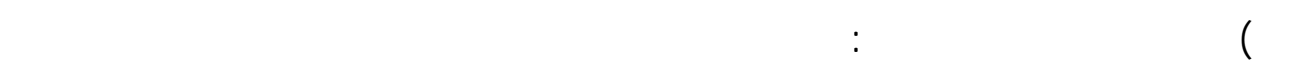

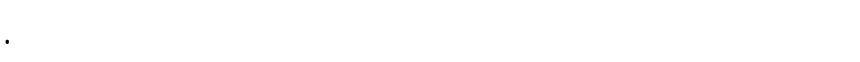

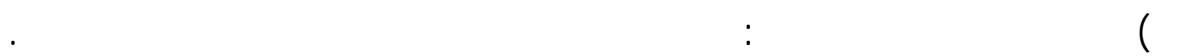

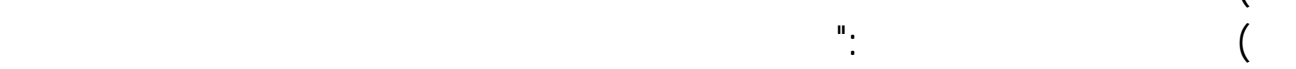

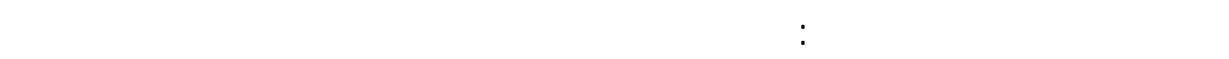

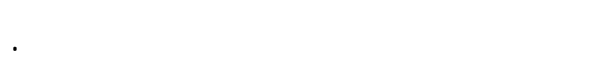

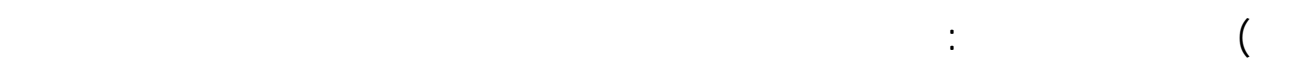

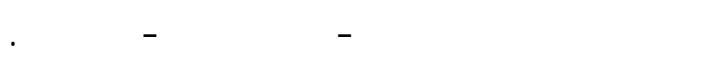

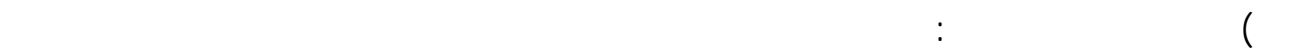

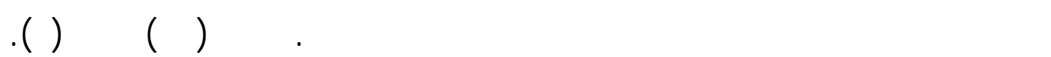

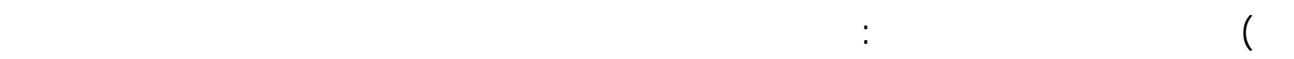

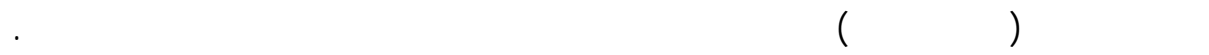

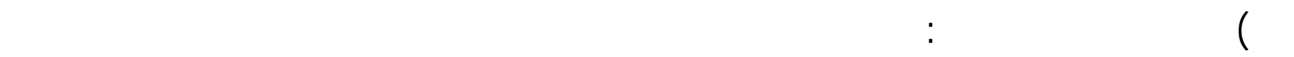

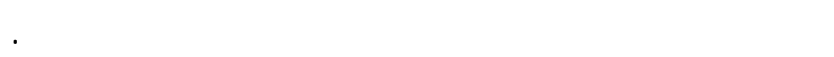
IV 1^) smart,j.c(1991).Higer Education of Theory and Research, vo'.VII.NEW YORK:Agathon press. 